\title{
Effect of build orientation on the fatigue properties of as-built Electron Beam Melted Ti-6Al-4V alloy.
}

\author{
Theo Persenot ${ }^{\mathrm{a}, *}$, Alexis Burr ${ }^{\mathrm{b}}$, Guilhem Martin ${ }^{\mathrm{b}}$, Jean-Yves Buffiere ${ }^{\mathrm{a}}$, Remy Dendievel ${ }^{\mathrm{b}}$, Eric Maire $^{\mathrm{a}}$ \\ ${ }^{a}$ INSA Lyon, CNRS, MATEIS, F-69621 Villeurbanne, France \\ ${ }^{b}$ Univ. Grenoble Alpes, CNRS, Grenoble INP, SIMAP, F-38000 Grenoble, France
}

\begin{abstract}
As-built Ti-6Al-4V thin parts were manufactured in three different orientations using EBM and characterized by laboratory X-ray tomography. Fatigue tests were performed. The comparison with results for machined samples from the literature showed a large reduction of fatigue strength. SEM observations of the fracture surfaces showed that surface defects which were identified as notch-like defects on tomographic images caused the failure. Their impact on fatigue results was rationalized by Kitagawa-Takahashi diagrams. A build orientation impact on the fatigue properties was observed and linked to its effect on defects distributions and crack growth. The limits of roughness measurements were also discussed. Keywords: Electron Beam Melting, Titanium alloys, Fatigue behavior, X-ray microtomography, As-built properties,
\end{abstract} Manufacturing orientation 2010 MSC: 00-01, 99-00

\section{Introduction}

Combining good mechanical properties with interesting thermal or acoustic properties is of great interest and, to this end, architectured materials are good candidates to replace monolithic materials. In particular, for industries where weight saving is also considered such as aeronautics industry, lattice structures are extremely promising, see e.g. [1], $[2],[3],[4],[5],[6],[7],[8]$. However, until recently, it was very challenging to build such metallic lattice structures with conventional processes as multiple steps were required, see e.g. [9], [10]. With the emergence of powder-bed based additive manufacturing techniques such as selective laser melting (SLM) and electron beam melting (EBM), producing such structures is becoming easier.

If series production is to be considered, one needs to determine reliable mechanical properties for the manufactured lattices, see e.g. [11], [12], [13], [14], [15]. As damage caused by cyclic mechanical loading is the main cause of failure for industrial parts, determining the fatigue properties of additively manufactured samples is mandatory. It has been demonstrated that the fatigue properties of Ti-6Al-4V EBM samples can be equivalent to those of the wrought materials

*Corresponding author. Tel.: +33686128527. E-mail address: theo.persenot@insa-lyon.fr 
1

when defects are removed by appropriate post building treatments, see e.g. [16], [17], [18], [19], [20], [21]. For example, in [18], [20], [21], Hot Isostatic Pressing (HIP) was performed on EBM samples prior to machining in order to respectively reduce internal porosity and remove the surface irregularities caused by the EBM process. Nevertheless, when complex geometries are considered (thin parts or lattice structures), conventional machining techniques are no longer usable and other appropriate surface treatments have to be considered. Some have already been investigated in the literature: chemical polishing [22], [23], [24], electrochemical polishing [25], [26], shot peening [27], [28] or abrasive flow machining [29] but, in most cases, the obtained surface finish does not match that of machined surfaces. This can partly explain why the development of lattice structures in the industry is still limited.

In addition, due to the layer by layer nature of the additive manufacturing processes, the orientation of one sample in the building chamber can affect its microstructure and mechanical properties, see e.g. [15] for a recent review. As a lattice structure is composed of struts built with different orientations, the impact of the build orientation on the defects and on the fatigue properties becomes a key issue.

Furthermore, for obvious geometrical considerations, the stress/strain distribution within lattice structures are complex; two types of lattices can be distinguished: the bending dominated structures and the stretching dominated ones [30]. For the latter, uniaxial tension and compression are the predominant loading modes. Consequently, the fatigue behaviour of individual struts in any stretching dominated structure can be analyzed based on the results of uniaxial fatigue tests. For both kinds of lattices, complex local loading conditions are known to occur at the vicinity of the nodes, see e.g. [31], [32], [33]. This critical point however falls outside the scope of this paper which mainly aims at characterizing the effect of the build orientation on the fatigue performance of as-built Ti-6Al-4V thin parts produced by EBM. To mimic the behaviour of struts, thin fatigue tensile specimens with a nominal diameter of $2 \mathrm{~mm}$ have been used. A method combining 3D X-ray microtomography imaging before and after the fatigue test with SEM observations of the fracture surfaces was developed in order to identify the critical defects. Correlations between the build orientation, the defects and the fatigue properties were finally established.

\section{Experimental procedures}

\subsection{Samples manufacturing}

Cylindrical fatigue tensile specimens with a $10 \mathrm{~mm}$ gauge length and a $2 \mathrm{~mm}$ nominal diameter were produced using an ARCAM A1 EBM machine and Ti-6Al-4V ELI powder. The chemical composition of the initial powder batch is given in Table 1 (Ti-6Al-4V grade 23). The EBM machine operated at $60 \mathrm{kV}$ accelerating voltage under a controlled pressure 

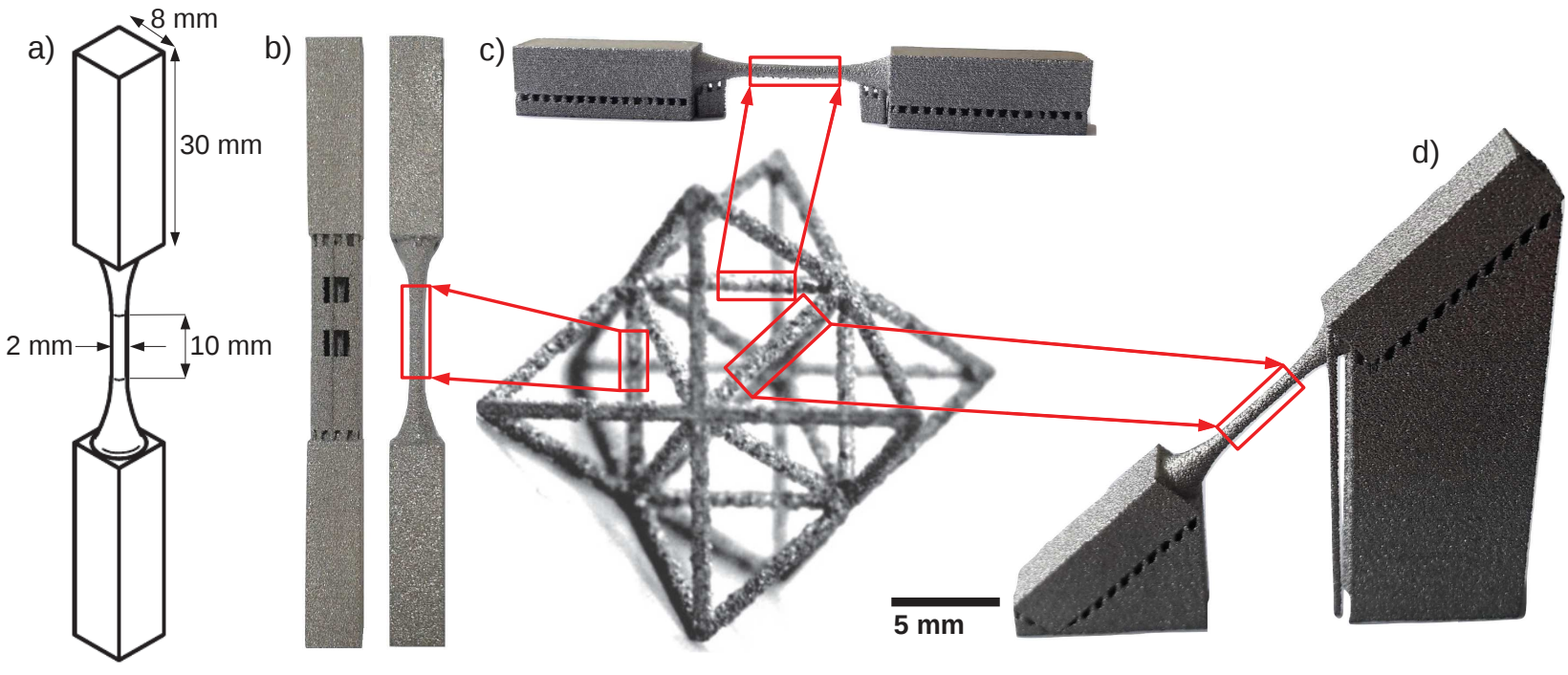

Figure 1: Geometry of the fatigue specimens representative of a single strut of any lattice structure (here, an octet truss). (a) 3D isometric view of the Computer Assisted Design input. (b-d) Photographs of a lattice unit cell and of the fatigue specimens manufactured in three different orientations before removal of the manufacturing supports (b,c and $\mathrm{d}$ for $90^{\circ}, 0^{\circ}$ and $45^{\circ}$ samples respectively).

of He of 2.10-3 mbar. $50 \mu m$ thick powder layers were deposited on a stainless steel plate, then slightly sintered with a defocused beam and finally selectively melted according to the input CAD geometry (Figure 1).

The small nominal diameter of the samples was chosen so as to be representative of a single strut of a lattice structure (large surface to volume ratio). These thin specimens were manufactured in three differents orientations: their tensile axis was either perpendicular (vertical sample), tilted at $45^{\circ}$ or parallel (horizontal sample) to the build plate, see Figure 1. Throughout this paper, the samples manufactured in these three orientations will be respectively referred to as $90^{\circ}$ samples, $45^{\circ}$ samples and $0^{\circ}$ samples. These three orientations have been chosen because they are representative of struts in any lattice structure, whatever its build orientation and unit cell. From a thermal point of view, $90^{\circ}$ samples are manufactured in optimized conditions (for each layer, the area to be melted stands over bulk material) whereas the bottom of the $0^{\circ}$ samples is directly manufactured on unmelted powder particles (limited thermal dissipation). The case of the $45^{\circ}$ samples stands in between these two opposite situations and those samples are representative of most struts with a tilted axis.

A preheating temperature of $\sim 730^{\circ} \mathrm{C}$ was maintained throughout the build. The standard "Melt" build theme recommended by ARCAM and defined in the EBM Control 3.2 software was used. The melting strategy consists in scanning the area defined by the CAD starting by the sample contours ( 2 contours). It is then followed by the hatching of the inner part of the CAD section with a snake-like pattern (line offset set to $0.1 \mathrm{~mm}$ and line order set to 1 ). The scanning direction was rotated by 90 after every layer. 
Table 1: Chemical composition of the initial Ti-6Al-4V powder batch used for this investigation.

\begin{tabular}{lllllllll}
\hline Elements & $\mathrm{Al}$ & $\mathrm{V}$ & $\mathrm{C}$ & $\mathrm{Fe}$ & $\mathrm{O}$ & $\mathrm{N}$ & $\mathrm{H}$ & $\mathrm{Ti}$ \\
\hline wt\% & 6.47 & 3.93 & 0.01 & 0.22 & 0.09 & 0.01 & 0.001 & Bal. \\
\hline
\end{tabular}

\subsection{X-ray tomography}

The full 3D characterization of the gauge length of the fatigue samples was obtained using laboratory X-ray tomography. The fatigue specimens were inspected in the as-built condition with a cone beam phoenix $\mid \mathrm{x}$-ray $\mathrm{V} \mid$ tome $\mid \mathrm{x}$ laboratory tomograph using a $2.5 \mu \mathrm{m}$ voxel size (spatial resolution of $\sim 4 \mu \mathrm{m}$ ). Detailed information on the setup can be found in [34]. 5 scans were required at different heights along the sample axis to image the whole gauge length. The following scanning parameters were used: voltage $\mathrm{V}=90 \mathrm{kV}$, current $\mathrm{I}=240 \mu \mathrm{A}$, exposure time $=333 \mathrm{~ms}, 720$ projections per scan. No filter was needed. The resulting scanning time per sample (over its entire length) was roughly 1 h. The reconstruction of the $3 \mathrm{D}$ images was performed using a standard filtered back projection method (phoenix datos x software). The reconstructed volumes were then post-treated and analyzed using Fiji software. The pore volume fraction was obtained by thresholding the 8 bits gray scale images. ${ }^{1}$.

Following the method initially suggested by Suard et al. [35], the tomographic images were used to evaluate the samples roughness. A series of profiles of the surface was extracted from a radial slice every $10^{\circ}$ around the sample circumference and used to compute an average measurement of the arithmetic (Ra) as well as the maximum (Rt) roughnesses (see [35] and [36] for details). The values obtained with this method have been compared to measurements performed with an INTRA2 Taylor Hobson profilometer.

\subsection{Fatigue testing}

As-built fatigue tensile specimens were tested at room temperature using a servo-hydraulic INSTRON 8516 fatigue testing machine equipped with a $5 \mathrm{kN}$ cell force. Constant amplitude stress controlled uni-axial tests were carried out with a frequency $\mathrm{f}=10 \mathrm{~Hz}$ (sinusoidal wave form) and a stress ratio $\mathrm{R}=0.1$ to comply with the aircraft industry requirements [37]). Because as-built sample cross section varies along the gauge length, the cyclic maximum and mean stress levels were calculated based on the average section along the gauge length determined from the tomographic scans of the samples. This definition was found to be more appropriate for stress calculation in this type of samples [36]. The fatigue tests were performed until failure or stopped after $10^{7}$ cycles. The fracture surfaces of the samples were observed using scanning

\footnotetext{
${ }^{1}$ Pores with a volume smaller than 8 voxels (cube of $2 * 2 * 2$ voxels) were disregarded in the analysis of the binary images
} 


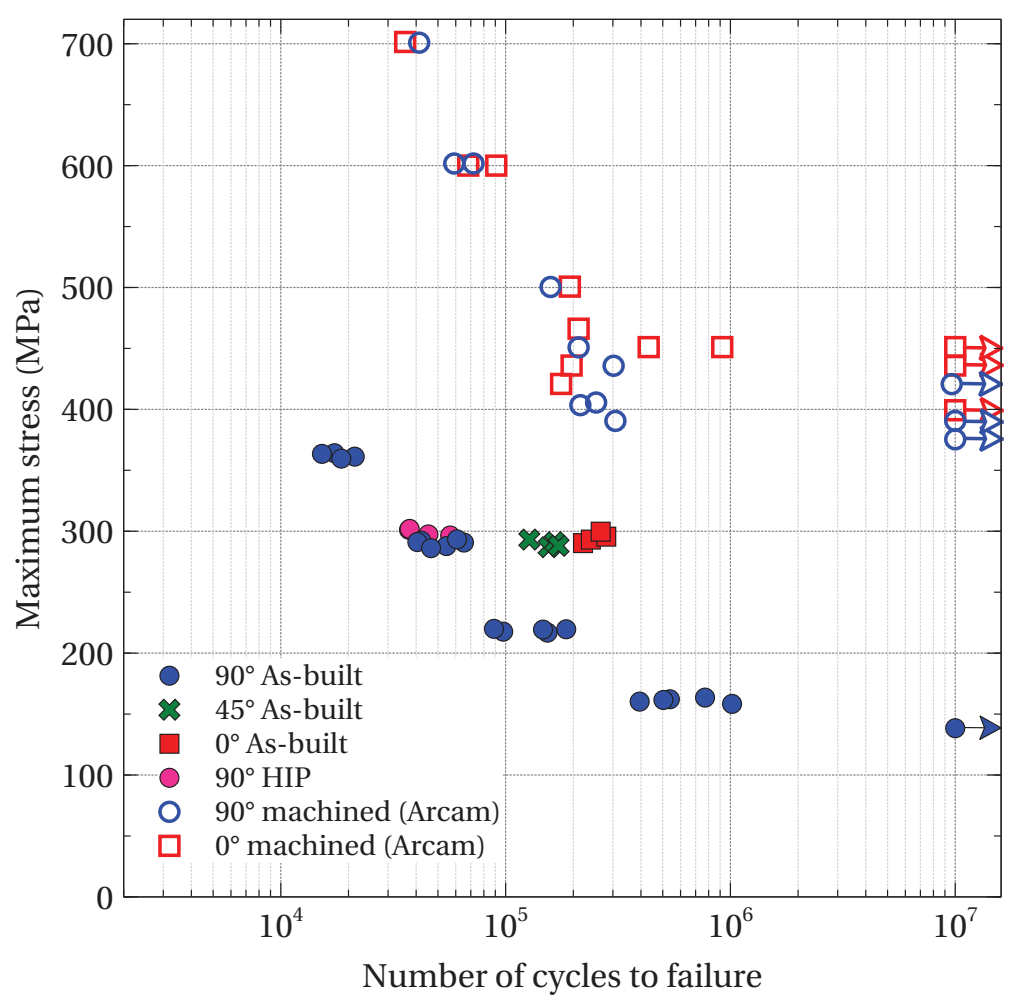

Figure 2: S-N curves for as-built fatigue samples fabricated by EBM with 3 different orientations: $0^{\circ}$ (red squares), $45^{\circ}$ (green crosses) and $90^{\circ}$ (blue dots). Hollow symbols correspond to data from ARCAM [38] on machined samples obtained by EBM.

electron microscopy under secondary electron contrast and the broken samples were imaged by X-ray tomography.

\section{Results}

\subsection{Fatigue properties}

The S-N curves of the as-built samples are presented in Figure 2 where results from the literature for machined samples have also been added (hollow symbols) [38]. The build parameters (powder, machine, build theme, layer thickness, ...) for these machined samples are the same as the ones used in this study but the samples geometry differs: ARCAM data were obtained on larger cylindrical tensile specimens that were machined from bulk materials. It is likely that this machining step has removed sub-surface pores as shown in [39]. For the $90^{\circ}$ samples, several stress levels were investigated in order to obtain fatigue lives ranging between $10^{4}$ and $10^{7}$ cycles. A clear reduction of the fatigue properties can be observed for the as-built samples tested in this work compared to machined samples. For instance, the fatigue limit $\sigma_{f}$ obtained at $10^{7}$ cycles is equal to $\sigma_{f}=140 \mathrm{MPa}$ whereas for machined $90^{\circ}$ samples, this value is of the order of $\sigma_{f}=400 \mathrm{MPa}[38]$. It can be seen from Figure 2 that the build orientation also has a significant impact on the measured fatigue properties. The $45^{\circ}$ and $0^{\circ}$ samples have been tested at a maximum stress level $\sigma_{\max }=290 \mathrm{MPa}$ corresponding to fatigue lives around 
$10^{5}$ cycles since this value is classically used in aeronautical design [37]. At this stress level, the average fatigue lives of the $90^{\circ}, 45^{\circ}$ and $0^{\circ}$ samples are respectively 50000,155000 and 250000 cycles. This effect of build orientation was not reported in the literature for the machined samples (red and blue hollow symbols in Figure 2).

In order to identify the failure mechanisms, the fracture surfaces of samples with different build orientations have been systematically examined by SEM. Three representative fracture surfaces are shown on Figure 3. The relatively large flat zone corresponds to the stable crack propagation regime, its size $a_{s t}$ scales with the fatigue lives $\left(a_{s t, 90^{\circ}}<a_{s t, 45^{\circ}}\right.$ $\left.<a_{s t, 0^{\circ}}\right)$. For the three specimens shown on Figure 3, the crack leading to failure initiates from a surface defect. The fracture surfaces of Figure 3 are also representative of what was observed at higher and lower stresses for the $90^{\circ}$ samples. Defects at the sample surface are therefore critical for the fatigue resistance, as already reported, see e.g. [39]. A detailed characterisation of those defects but also of those present in the bulk is presented in the next section.

\subsection{Characterization of defects produced by the EBM process}

\subsubsection{Porosity}

The pore volume fraction in as-built samples estimated from the 3D images is reported in Table 2 for each build orientation. A low value of internal porosity $(<0.05 \%)$ was measured in the gauge volume of all the samples, confirming the ability of EBM to produce almost fully dense bulk samples. The vast majority of the pores exhibited a nearly spherical morphology with an average diameter of $\sim 20 \mu \mathrm{m}$. Tammas-Williams et al. [40] showed that such pores, usually named gas pores, are already present in the initial powder particles. Very few internal lack-of-fusion defects were observed.

Table 2: Effect of the build orientation on the as-built EBM samples properties: average section, internal porosity and roughnesses. The average values and the standard deviations are reported. For comparison, the nominal section is $3.14 \mathrm{~mm}^{2}$.

\begin{tabular}{|c|c|c|c|c|c|c|}
\hline Material & Average & Internal & & $\operatorname{Ra}(\mu m)$ & & \\
\hline characterization & section $\left(\mathrm{mm}^{2}\right)$ & Porosity (\%) & Average value & Upper surface & Lower surface & \\
\hline $0^{\circ}$ samples & $2.67 \pm 0.08$ & $0.035 \pm 0.005$ & $30.6 \pm 2.2$ & $11.0 \pm 2.1$ & $56.9 \pm 7.7$ & $515 \pm 31$ \\
\hline $45^{\circ}$ samples & $2.43 \pm 0.03$ & $0.040 \pm 0.007$ & $36.2 \pm 2.3$ & $32.4 \pm 2.9$ & $42.3 \pm 6.3$ & $350 \pm 46$ \\
\hline $90^{\circ}$ samples & $2.74 \pm 0.01$ & $0.025 \pm 0.004$ & $44.0 \pm 3.6$ & $\mathrm{~N} / \mathrm{A}$ & $\mathrm{N} / \mathrm{A}$ & $390 \pm 52$ \\
\hline
\end{tabular}

Figure 4 shows projected views of the internal pores for the three differents orientations. A sub-surface circular region with a higher density of pores can be observed for the three orientations. Its width decreases when the build orientation goes from $90^{\circ}$ to $0^{\circ}$. In the central part of the latter, some horizontal patterning with a higher density of pores can also be identified. 


\subsubsection{Roughness measurements and surface irregularities}

The roughnesses values calculated for samples manufactured in the three different orientations are reported in Table 2. The lowest average roughness $(\mathrm{Ra})$ is obtained for the horizontal samples $\left(0^{\circ}\right)$ whereas the vertical samples $\left(90^{\circ}\right)$ show the highest values $(30.6 \pm 2.24 \mu \mathrm{m}$ and $44.0 \pm 3.6 \mu \mathrm{m}$ respectively). Regarding the maximum roughness (Rt), the lowest and highest values are obtained respectively for the $45^{\circ}$ samples and $0^{\circ}$ samples $(350 \pm 45.5 \mu m$ and $515 \pm 30.5$ $\mu m$ respectively). The build orientation has clearly an impact on the surface roughness of as-built samples. Additional roughness measurements performed on some $90^{\circ}$ samples with a profilometer show a good agreement between the two different methods: the average value of Ra obtained by profilometry is $36.9 \mu m$ (v.s. $44.0 \mu m$ from tomographic images).

The 3D rendering of the sample surfaces shown in Figure 5 illustrates the effect of the build orientation at a macroscopic scale (visual aspect of the sample surface). In the case of $0^{\circ}$ (Figure $5 \mathrm{~b}$ and $5 \mathrm{~d}$ ) and $45^{\circ}$ samples (Figure $5 \mathrm{c}$ and Figure 5e), a clear difference between the upper and lower sample surfaces can be observed. In both cases, the upper surface is smoother than the lower one. This tendency is more pronounced for the horizontally manufactured samples: the upper surface of the $0^{\circ}$ sample looks quite smooth while the successive manufacturing layers are visible on the $45^{\circ}$ sample upper surface (Figure 5g and 5i respectively). As there is no upper nor lower surface for the gauge length of $90^{\circ}$ samples, the surface state of those samples shows no evolution along its circumference (Figure 5f).

The average roughnesses of the upper and lower surfaces were computed for the $0^{\circ}$ and $45^{\circ}$ samples (Table 2). As could be expected, in both cases, the upper and lower surfaces exhibit respectively lower and higher Ra values than the average ones. It is worth pointing out that for both build orientations, the roughness of the lower surfaces meets $\left(45^{\circ}\right.$ samples) or exceeds $\left(0^{\circ}\right.$ samples $)$ the average value of $90^{\circ}$ samples which show the highest average Ra value.

\subsubsection{Surface defects and critical defect identification}

The surface irregularities generated by the EBM process can be observed on radial tomographic slices as shown in Figure 6. Two different types of surface defects can be observed: unmelted powders stuck to the struts and irregularities in the layer stacking, the so-called "plate-pile" like stacking defects described in [35],[23], [41]. The latter are observed in the $45^{\circ}$ and $90^{\circ}$ samples and they can sometimes lead to notch-like defects [36]. These defects (red arrows in Figure 6d and 6f) are always oriented perpendicularly to the building direction. There are fewer defects of this type in the $45^{\circ}$ samples than in the $90^{\circ}$ whereas hardly any can be observed in the $0^{\circ}$ samples (for example, no notch-like defect can be found in the radial slice in Figure 6a). A schematic illustration of the different types of defects observed in EBM as-built samples is shown on Figure 7.

In order to identify the defect that lead to the fatal crack, tomographic scans performed before and after failure were 
acquired and compared. This enables to determine the tomograpic slice at which failure occured, see Figure 8 . Then, from the SEM image of the fracture surface and a transverse reconstructed slice, the critical defect can be identified and one can get access to its exact geometry (size and shape) on the tomographic images before the fatigue test. For all investigated samples, and regardless of their build orientation, the crack was found to initiate from a "plate-pile" like stacking defect. In the case of the $45^{\circ}$ and $90^{\circ}$ samples, notch-like defects were observed at the level of the stacking irregularity at which the cracks initiated. None were detected for the $0^{\circ}$ samples. Example of defects leading to the failure are shown in Figure 9 for the three build orientations. 


\section{Discussion \\ 4.1. Impact of as-built state on fatigue properties}

The fatigue results presented in Figure 2 show that, for every build orientation considered, the fatigue resistance of as-built samples is considerably lower than that of the machined samples [38]. The as-built samples were manufactured using the same type of machine, the same powder and the same standard "Melt" build theme with the same layer thickness than ARCAM used in reference [38]. The microstructure of the as-built samples was reported in a previous study [36] and was found to be similar to the one reported by ARCAM and other literature sources (see for example [20], [42] and [43]) despite the size difference between both kinds of samples: fine $\alpha$-laths $(\sim 1 \mu m$ width) separated by some residual $\beta$ phase.

For both SLM and EBM Ti-6Al-4V alloys machined samples, the reported crack initiation sites were either internal, sub-surface or surface defects, see for example [21], [44], [45] or [46]. Those defects were often gas pores which were internal in the as-built state and brought to the surface or sub-surface during machining ([39], [45]). Such internal or sub-surface defects were also observed in the as-buit samples of this study (Figure 4) but they were never found to be responsible for the sample failure. Instead, the crack leading to failure initiated from stacking irregularities (Figure 3) which were notch-like defects in the case of $45^{\circ}$ and $90^{\circ}$ samples (radial slices in Figure 9). Similar initiation sites were reported for as-built SLM manufactured samples [47].

The ability of a defect to initiate a fatigue crack can be assessed through its stress concentration factor $K_{t}[48]$. A larger local stress results in an increased level of plasticity which leads to crack initiation because of slip irreversibility. In what follows, $K_{t}$ is used to compare the harmfulness of pores (internal or sub-surface) and that of "plate-pile" like stacking defects. A detailed analysis of the problem would theorically require the calculation of the local plastic strain concentrations induced by the defects. However, such calculations are computationally intensive specially in the cyclic case. Besides, Tammas-Williams et al. [49] have shown by FE calculations that, in the neighborhood of a pore, the localizations of plastic strain concentrations correspond with a good accuracy to the zones where elastic strain concentrations occur. In the rest of the discussion, therefore, only elastic strain concentrations are considered. With this assumption, the stress concentration factor $K_{t}$ of an internal spherical pore in an infinite elastic material is lower than 2 (perfect sphere). If this pore approaches the surface, its $K_{t}$ can reach values of the order of 5 [50].

Notch-like defects (see Figure 7) can be modelled as elliptical notches at the sample surface with a radius of curvature 
at the tip $\rho$ and a depth $a$ (Figure 7) for which the following classical formula can be used:

$$
K_{t}=1+2 \sqrt{a / \rho}
$$

The radius of curvature $\rho$ at the tip of the elliptical notch is equal to $b / a$ where $b$ is the "thickness" of the notch. From Figure 6 , typical values of $a / b$ larger than 10 can be measured, leading to very large values of $K_{t}\left(\right.$ for $\left.a / b=10, K_{t}=21\right)$. This impact of the aspect ratio of the defect on the $K_{t}$ values was also reported by Tammas-Williams [49]. Such large $K_{t}$ values clearly explain why cracks systematically initiate at notch-like defects and not at internal or sub-surface pores.

In order to check that the important loss of fatigue performance observed for the as-built state is not related to the presence of internal and sub-surface pores, a HIP treatment $\left(920^{\circ} \mathrm{C}, 100 \mathrm{MPa}\right.$ for 2 hours $)$ was applied to as-built $90^{\circ}$ samples. X-ray tomography scans were performed before and after the treatment: with the spatial resolution of laboratory tomography $(\sim 4 \mu \mathrm{m})$, no internal pore were detected after the HIP treatment as shown in Figure 10 . No impact on the fatigue properties was observed: the HIP treated samples had the same fatigue lives than the as-built samples (pink v.s. blue dots in Figure 2). This demonstrates that, as far as as-built samples are concerned, the internal pores (and their removal) have no impact on the fatigue life. The systematic HIP treatment performed on machined samples $(25 \%$ improvement of the fatigue limit $\sigma_{f}$, see [21], [43]) does not seem necessary for as-built samples.

If notch-like defects are more likely to initiate a crack than internal pores, this does not always mean that such a crack will propagate and lead to the failure of the sample. Consequently, there is a need to consider the ability of such cracks to propagate, which will be the focus of the next section.

\subsection{Fatigue properties and as-built state: impact of build orientation}

The comparison of the fatigue lives of as-built samples submitted to medium stress levels $\left(\sigma_{\max }=290 \mathrm{MPa}\right)$ shows an impact of the build orientation (Figure 2) whereas no significant difference in fatigue properties can be found between the two orientations $\left(90^{\circ}\right.$ and $\left.0^{\circ}\right)$ of the machined samples (Figure 2). This impact on the fatigue properties is thus most likely due to the influence of the build orientation on the surface defects.

A traditional approach for designing components with materials containing defects is the damage tolerance approach. The Kitagawa-Takahashi diagram [51] can be used to relate the fatigue properties of a material depending on the size of the defects that it contains. Beretta and Romano [52] have recently shown that the Kitagawa-Takahashi diagram can reasonably well describe the fatigue properties of Ti-based and Al-based alloys fabricated by AM. The defects are considered as cracks and the stress intensity factor that they generate is compared to the crack growth threshold of the material in order to assess their ability to propagate. It has been shown above that, for the material studied here, the cracks 
leading to failure initiate from notch-like surface defects with a crack-like shape. Several approaches can be considered for building the Kitagawa-Takahashi diagram (see for example [53]). The formulation based on the El Haddad's empirical parameter $a_{0}[54]$ is being used here:

$$
a_{0}=\frac{1}{\pi}\left(\frac{\Delta K_{t h}}{Y * \Delta \sigma_{f}}\right)^{2}
$$

where $\mathrm{Y}$ depends on the crack location (typically $Y=0.65$ for a surface crack), $\Delta \sigma_{f}$ is the stress range at the fatigue limit $\sigma_{f}$ and $\Delta K_{t h}$ is the crack growth threshold of the material (more details can be found in [55]).

The fatigue limit $\sigma_{f}$ considered here is the one obtained for samples free of surface defects, i.e. machined samples. Published results of standard fatigue crack growth tests on Ti-6Al-4V samples additively manufactured by EBM are used for the $\Delta K_{t h}$ values. Several studies ([56], [57], [58], [59], [60]) have been compared and the minimum, average and maximum values obtained from them have been reported in Table 3 . For EBM machined samples, the $\Delta K_{t h}$ values provided by these studies were found to be dependent on the orientation of the notch with respect to the building direction, i.e. perpendicular (horizontal) or parallel (vertical). This dependency has been linked to the microstructural features such as basket-weave and Widmanstätten microstructures which impact the nucleation and the short crack propagation [52], [61]. The values used to plot the Kitagawa diagram displayed in Figure 11 are reported in Table 3.

Table 3: Intrinsic crack size $a_{0}$ depending on the $\Delta K_{t h}$ values found in the literature. crack perpendicular to the building direction crack parallel to the building direction

\begin{tabular}{lcccccc} 
& $\Delta K_{\text {th, min }}$ & $\Delta K_{\text {th,av }}$ & $\Delta K_{\text {th, max }}$ & $\Delta K_{\text {th }, \text { min }}$ & $\Delta K_{\text {th,av }}$ & $\Delta K_{\text {th, max }}$ \\
$\Delta K_{\text {th }}(\mathrm{MPa} \sqrt{m})$ & 3.4 & 3.6 & 3.8 & 4.2 & 4.9 & 5.7 \\
\hline$a_{0}(\mu \mathrm{m})$ & 53 & 60 & 66 & 81 & 110 & 149 \\
\hline
\end{tabular}

The fatigue results obtained for some as-built samples have then been reported in Figure 11. The defect size $a$ was determined using the approach developed by Murakami [62] which considers the projected area of the defect perpendicular to the load axis area so that: $a=\sqrt{\text { area }}$. The resulting points are represented in blue, green and red symboles for respectively the $90^{\circ}, 45^{\circ}$ and $0^{\circ}$ samples. As shown in Figure 6, the notches responsible for the samples failure are perpendicular to the building direction for $45^{\circ}$ and $90^{\circ}$ samples whereas they are parallel to it for the $0^{\circ}$ samples. The red and blue curves (crack growth respectively parallel and perpendicular to the build direction) will therefore be used respectively for the $0^{\circ}$ samples (red) and the $45^{\circ}$ and $90^{\circ}$ samples (blue).

For samples with an important surface roughness, it is quite difficult, based on X-ray tomography images, to distinguish 
between the beginning of the surface defect and the surface variations in the vicinity of the defect. As a result, the SEM images of the fracture surfaces (Figure 3) were used to obtain the projected size of the crack which has lead to fracture in order to check wether the Kitagawa-Takahashi approach is appropriate. Figure 2 shows that for $90^{\circ}$ samples, the knee region of the Wöhler curve correspond to a number of cycles of the order of $\sim 2$ to $3.10^{5}$ cycles. Broken samples with a fatigue life larger than this number of cycles can be placed directly on the Kitagawa-Takahashi diagram. As explained, however, lots of points on the Wöhler curve correspond to specimens with fatigue lives of the order of $10^{5}$ cycles, for the three orientations. The points corresponding to those specimens cannot therefore be directly inserted on the Kitagawa-Takahashi diagram. Two different approaches have been tested to overcome this problem.

The first one suggested by Beretta and Romano [52] consists in extrapolating the fatigue lives from $10^{5}$ cycles to larger fatigue lives corresponding to the knee region of the Wöhler curve. This has been done for the three orientations and the results are shown on Figure 11a. On this figure, the number of cycles used for extrapolation for $0^{\circ}$ and $45^{\circ}$ samples varies from 3 to $6.10^{5}$ cycles which corresponds to the scatter of the data obtained at the knee-point for the Wöhler curve of the $90^{\circ}$ samples.

The second approach follows the work of Ciavarella and Monno who proposed a method to extend the KitagawaTakahashi diagram to finite lives prediction. The procedure can be briefly summarized as follow (for details, see [63]): when the fatigue resistance at a given number of cycles $N_{f l}$ is sought, both the left and the right part of the diagram should be modified. For the left part, the fatigue limit is defined as the stress amplitude corresponding to $N_{f l}$ on the Wöhler curve of the machined samples (Figure 2). For the right part of the diagram, a propagation law is assumed and integrated for each $N_{f l}$. Here, a propagation law in the Paris regime taken from the work of Seifi et al. [57] was used for both $0^{\circ}$ and $90^{\circ}$ orientations. The results of this second approach are shown on Figure $11 \mathrm{~b}\left(90^{\circ}\right.$ samples $)$ and Figure $11 \mathrm{c}$ $\left(0^{\circ}\right.$ and $45^{\circ}$ samples $)$.

Figure 11a shows that once the extrapolation is being carried out on the Wöhler curve, the experimental points fall reasonably well on the Kitagawa-Takahashi curves for the 3 investigated orientations. For $0^{\circ}$ samples, the predictions are no longer conservative once the extrapolated number of cycles used exceeds $4.10^{5}$ cycles whereas, for $45^{\circ}$ samples, the predictions are always conservative and are improving when the number of cycles used for extrapolation increases.

The results from the second approach which aims at calculating pseudo Kitagawa-Takahashi diagrams for a given number of cycles are contrasted: good predictions are obtained for $0^{\circ}$ and $45^{\circ}$ samples (with very limited date available, see Figure 11c) but for $90^{\circ}$ samples, the fatigue resistance is clearly overestimated for fatigue lives shorter than the knee point of the Wöhler curve (Figure 11b). One reason might be that the cracks emanating from the notch-like defects might have a typical short crack behaviour with a faster growth rate than the one predicted by the classical Paris law established 
1

for long cracks (for a more detailed discussion on that point, see [63]).

The Kitagawa approach shows that the critical parameters for assessing the fatigue strength are the crack growth threshold $\Delta K_{t h}$ and the stress intensity factor range $\Delta K$ which has been calculated through the $\sqrt{\text { area }}$ parameter.

As mentioned earlier, the $\Delta K_{t h}$ values found in the literature for $0^{\circ}$ samples are higher than the ones found for $90^{\circ}$ samples. Furthermore, Figure 3 shows that the build orientation has a direct effect on the surface defects size: $\sqrt{a r e a}_{90}$. $>\sqrt{a r e a}_{45^{\circ}}>\sqrt{a r e a}_{0^{\circ}}$. Thus, $0^{\circ}$ samples contain smaller critical surface defects as well as a microstructure which is more resistant to crack growth. Both factors can account for the longer fatigue lives measured for these samples.

In addition, even in the case of similar $\sqrt{a r e a}$ values, some authors have shown that there is an influence of the defect orientation on the fatigue strength. In a recent paper, Lorenzino [64] demonstrated that the $\sqrt{\text { area }}$ parameter tends to be less predictive of the defect harmfulness when the angle between the load axis and the defect major axis is decreased from $90^{\circ}$ up to $30^{\circ}$, the harmfulness of the latter being slightly overestimated. It was also shown in [64] that this tendency was exacerbated when the yield strength of the material was high which is typically the case of the EBM Ti-6Al-4V alloy studied here (yield strength $=850 \mathrm{MPa},[36],[43]$ ). As shown in Figure 6, the notch-like defects of $90^{\circ}$ and $45^{\circ}$ samples are respectively perpendicular and tilted at $45^{\circ}$ with respect to the loading direction. This could explain the discrepancy in terms of fatigue lives between $90^{\circ}$ and $45^{\circ}$ samples: the defects found in the $90^{\circ}$ samples present the most harmful tilt. Both effects could therefore account for the observed dependence of the fatigue strength on the build orientation.

Another factor that can impact the fatigue properties is the number of defects which can initiate a crack. Figure 6 shows the differences between the density of surface defects within the gauge length of the three types of samples. Hardly any notch-like defects can be identified in the $0^{\circ}$ samples whereas many can be observed in the $90^{\circ}$ samples, $45^{\circ}$ samples being somewhere between those two cases (Figure 6). Even though the fatigue strength should be linked to the extreme values of the defects distribution [65], a larger number of defects increases the probability of having one that is critical and could also explain the influence of the build orientation on fatigue lives. A thorough study of the defects distributions for each build orientation would be required in order to confirm this tendency.

\subsection{Notch-like defects detection and fatigue life prediction: is roughness the appropriate index ?}

From an industrial point of view, it might be interesting- or even critical- to be able to detect the presence of the notch-like surface defects by non-destructive tests (NDT) and to link fatigue properties to standard parameters such as the surface roughness.

On the one hand, the notches leading to failure are visible on the X-ray tomographic images (see Figure 6 and Figure 9) when a low voxel size is used ( $\sim 2.5 \mu \mathrm{m}$ in this case). However, only parts with a size of the order of $1 \mathrm{~cm}$ could be 
imaged by tomography because of the limited X-ray energy and of the need to use a small specimen-to-source distance. This size is likely to be too small for practical application of the lattice in macroscopic parts.

On the other hand, such thin and deep defects are systematically overlooked by classical profilometry as shown by the measurements performed on $90^{\circ}$ samples: compared to the Ra value based on tomography scans where crack-like notches are detected, the average value of Ra obtained by profilometry is $16 \%$ smaller $(36.9 \mu m$ v.s. $44 \mu m)$. This technique is therefore not suited for the detection of notches and, as a result, only X-ray tomography based roughness measurements might be used for fatigue life prediction.

Vertically (respectively horizontally) manufactured samples with their large (respectively limited) population of stacking defects (Figure 6) present the highest (respectively the lowest) Ra value, see Table 2. A good correlation seems to appear between Ra and the fatigue life, larger Ra values giving shorter fatigue lives (Table 2 and Figure 2). Nevertheless, fatigue failure is always triggered by notch-like defects (Figure 9) which are seldom present at the surface. Their impact on the Ra measurements is thus limited. This means that, in spite of the apparent correlation reported above, Ra cannot be the relevant parameter for predicting the fatigue life in the case as-built EBM samples.

The Rt parameter which describes the local roughness variations could potentially be a more relevant parameter. However, the Rt ranking differs from the fatigue resistance ranking: $0^{\circ}$ samples have the longest fatigue lives but also the highest Rt values, see Table 2. Two facts can explain this observation. First, the method used for the roughnesses calculation (see e.g. [35], [36]) extracts surface profiles every $10^{\circ}$ along the circumference of the gauge length. Very local surface irregularities such as notch-like defects are thus more likely to be overlooked. Second, the Rt value considers the distance between the highest and the lowest point of the surface but does not describe the shape of the corresponding defects. A large Rt value can be caused by a deep stacking defect ( $45^{\circ}$ and $90^{\circ}$ samples) with a large radius of curvature or even by some large protuberances caused by the thermal process, justifying why no correlation can be made between the $\mathrm{Rt}$ values and the fatigue lives.

\section{Conclusion}

For additively manufactured lattice structures, conventional machining cannot be used to improve the surface state. Furthermore, the struts forming the lattice are built in many different orientations. Determining the impact of as-built state and of build orientation on the fatigue properties is mandatory and was the aim of the work presented here. The main conclusions can be drawn as follows:

- The detrimental effect of the as-built surface state on the fatigue resistance of individual struts was clearly shown; 
designing lattice structures against fatigue using data obtained on machined samples is unsafe and can lead to erroneous conclusions.

- The build orientation impacts the fatigue properties of as-built samples because of its influence on the shape, size and number of notch-like defects from which fatal cracks initiate.

- Horizontal and vertical samples were shown to be respectively the best and worst samples in terms of fatigue lives.

- Considering the fabrication of lattice structures, it might be interesting to limit the number of vertical struts and to build struts as much as possible in the horizontal direction.

- Using roughness measurements of as-built AM samples to infer information regarding the fatigue properties is unsafe since these measurements do not reveal the thin and deep notch-like defects.

\section{Acknowledgements}

The authors would like to thank the French Agence Nationale de la Recherche and the French Fondation de Recherche pour l'Aéronautique et l'Espace for the financial support of this project entitled "Fabrication Additive et FAtigue de Structures Cellulaires Intgres en AEronautique" (FA2SCINAE-ANR-15-CE08-0038-03).

\section{References}

[1] N. A. Fleck, V. S. Deshpande, M. F. Ashby, Micro-architectured materials: past, present and future, Proceedings of the Royal Society of London A: Mathematical, Physical and Engineering Sciences 466 (2121) (2010) 2495-2516. arXiv : http://rspa.royalsocietypublishing.org/content/466/2121/2495.full.pdf, doi:10.1098/rspa.2010.0215. URL http://rspa.royalsocietypublishing.org/content/466/2121/2495

[2] M. Ashby, Designing architectured materials, Scripta Materialia 68 (1) (2013) 4-7, architectured Materials. doi: https://doi.org/10.1016/j.scriptamat.2012.04.033.

URL http://www.sciencedirect.com/science/article/pii/S1359646212002965

[3] M. Ashby, Y. Bréchet, Designing hybrid materials, Acta Materialia 51 (19) (2003) 5801 - 5821, the Golden Jubilee Issue. Selected topics in Materials Science and Engineering: Past, Present and Future. doi:https://doi.org/10. 1016/S1359-6454(03)00441-5.

URL http://www.sciencedirect.com/science/article/pii/S1359645403004415

[4] L. J. Gibson, M. F. Ashby, Cellular solids: structure and properties, Cambridge university press, 1999. 
[5] A. Evans, J. Hutchinson, M. Ashby, Multifunctionality of cellular metal systems, Progress in Materials Science 43 (3) (1998) 171 - 221. doi:https://doi.org/10.1016/S0079-6425(98)00004-8.

URL http://www.sciencedirect.com/science/article/pii/S0079642598000048

[6] A. Evans, J. Hutchinson, N. Fleck, M. Ashby, H. Wadley, The topological design of multifunctional cellular metals, Progress in Materials Science 46 (3) (2001) 309 - 327. doi:https://doi.org/10.1016/S0079-6425(00)00016-5. URL http://www.sciencedirect.com/science/article/pii/S0079642500000165

[7] T. A. Schaedler, A. J. Jacobsen, A. Torrents, A. E. Sorensen, J. Lian, J. R. Greer, L. Valdevit, W. B. Carter, Ultralight metallic microlattices, Science 334 (6058) (2011) 962-965. arXiv:http://science.sciencemag.org/content/334/ 6058/962.full.pdf, doi:10.1126/science.1211649.

URL http://science.sciencemag.org/content/334/6058/962

[8] H. N. Wadley, Multifunctional periodic cellular metals, Philosophical Transactions of the Royal Society of London A: Mathematical, Physical and Engineering Sciences 364 (1838) (2006) 31-68. arXiv:http://rsta. royalsocietypublishing.org/content/364/1838/31.full.pdf, doi:10.1098/rsta.2005.1697. URL http://rsta.royalsocietypublishing.org/content/364/1838/31

[9] G. W. Kooistra, V. S. Deshpande, H. N. Wadley, Compressive behavior of age hardenable tetrahedral lattice truss structures made from aluminium, Acta Materialia 52 (14) (2004) 4229 - 4237. doi:https://doi.org/10.1016/j. actamat.2004.05.039.

URL http://www.sciencedirect.com/science/article/pii/S1359645404003131

[10] G. W. Kooistra, H. N. Wadley, Lattice truss structures from expanded metal sheet, Materials and Design 28 (2) (2007) 507 - 514. doi:https://doi.org/10.1016/j.matdes.2005.08.013.

URL http://www.sciencedirect.com/science/article/pii/S0261306905002438

[11] S.-I. Park, D. W. Rosen, S. kyum Choi, C. E. Duty, Effective mechanical properties of lattice material fabricated by material extrusion additive manufacturing, Additive Manufacturing 14 (2014) 12 - 23, inaugural Issue. doi:https: //doi.org/10.1016/j.addma.2014.07.002.

URL https://www.sciencedirect.com/science/article/pii/S2214860414000049

[12] E. Hernndez-Nava, C. Smith, F. Derguti, S. Tammas-Williams, F. Lonard, P. Withers, I. Todd, R. Goodall, The effect of density and feature size on mechanical properties of isostructural metallic foams produced by additive manufacturing, Acta Materialia 85 (Supplement C) (2015) 387 - 395. doi:https://doi.org/10.1016/j.actamat. 
2014.10 .058$.

URL http://www.sciencedirect.com/science/article/pii/S1359645414008222

[13] L. Yang, O. Harrysson, H. West, D. Cormier, Modeling of uniaxial compression in a 3d periodic re-entrant lattice structure, Journal of Materials Science 48 (4) (2013) 1413-1422. doi:10.1007/s10853-012-6892-2.

URL https://doi.org/10.1007/s10853-012-6892-2

[14] S.-I. Park, D. W. Rosen, E. Chad, Duty. comparing mechanical and geometrical properties of lattice structure fabricated using electron beam melting, in: Solid Freeform Fabrication Proceedings, Vol. 1, 2015, pp. 1359-1370.

[15] J. J. Lewandowski, M. Seifi, Metal additive manufacturing: A review of mechanical properties, Annual Review of Materials Research 46 (1) (2016) 151-186. arXiv:https://doi.org/10.1146/annurev-matsci-070115-032024, doi:10.1146/annurev-matsci-070115-032024.

URL https://doi.org/10.1146/annurev-matsci-070115-032024

[16] L. Murr, E. Esquivel, S. Quinones, S. Gaytan, M. Lopez, E. Martinez, F. Medina, D. Hernandez, E. Martinez, J. Martinez, S. Stafford, D. Brown, T. Hoppe, W. Meyers, U. Lindhe, R. Wicker, Microstructures and mechanical properties of electron beam-rapid manufactured ti6al4v biomedical prototypes compared to wrought ti6al4v, Materials Characterization 60 (2) (2009) 96 - 105. doi:http://dx.doi.org/10.1016/j.matchar.2008.07.006.

URL http://www.sciencedirect.com/science/article/pii/S1044580308002076

[17] P. Edwards, A. O’Conner, M. Ramulu, Electron Beam Additive Manufacturing of Titanium Components: Properties and Performance, Journal of Manufacturing Science and Engineering 135 (6) (2013) 061016. doi : 10.1115/1.4025773. URL http://manufacturingscience.asmedigitalcollection.asme.org/article.aspx?doi=10.1115/1. 4025773

[18] E. Brandl, C. Leyens, F. Palm, Mechanical Properties of Additive Manufactured Ti-6Al-4V Using Wire and Powder Based Processes, IOP Conference Series: Materials Science and Engineering 26 (2011) 012004. doi: $10.1088 / 1757-899 x / 26 / 1 / 012004$.

URL http: //stacks.iop.org/1757-899X/26/i=1/a=012004?key=crossref . c362f0236ee048bdb0a9dfeda93401d5

[19] H. K. Rafi, N. V. Karthik, H. Gong, T. L. Starr, B. E. Stucker, Microstructures and mechanical properties of ti6al4v parts fabricated by selective laser melting and electron beam melting, Journal of Materials Engineering and Performance 22 (12) (2013) 3872-3883. doi:10.1007/s11665-013-0658-0.

URL http://dx.doi.org/10.1007/s11665-013-0658-0 
[20] U. Ackelid, M. Svensson, Additive manufacturing of dense metal parts by electron beam melting, in: Proceedings of the Materials Science and Technology Conference, Pittsburgh, PA, USA, Vol. 2529, 2009.

[21] P. Li, D. Warner, A. Fatemi, N. Phan, Critical assessment of the fatigue performance of additively manufactured ti6al4v and perspective for future research, International Journal of Fatigue 85 (2016) 130 - 143. doi:http://dx. doi.org/10.1016/j.ijfatigue.2015.12.003.

URL http://www.sciencedirect.com/science/article/pii/S0142112315004399

[22] C. de Formanoir, M. Suard, R. Dendievel, G. Martin, S. Godet, Improving the mechanical efficiency of electron beam melted titanium lattice structures by chemical etching, Additive Manufacturing 11 (2016) 71-76. doi:10.1016/j . addma. 2016.05.001.

URL http://dx.doi.org/10.1016/j.addma.2016.05.001

[23] P. Lhuissier, C. de Formanoir, G. Martin, R. Dendievel, S. Godet, Geometrical control of lattice structures produced by ebm through chemical etching: Investigations at the scale of individual struts, Materials and Design 110 (2016) 485 - 493. doi:http://dx.doi.org/10.1016/j.matdes.2016.08.029.

URL http://www.sciencedirect.com/science/article/pii/S0264127516310929

[24] B. V. Hooreweder, Y. Apers, K. Lietaert, J.-P. Kruth, Improving the fatigue performance of porous metallic biomaterials produced by selective laser melting, Acta Biomaterialia 47 (2017) 193 - 202. doi:https://doi.org/10.1016/ j.actbio.2016.10.005.

URL http://www.sciencedirect.com/science/article/pii/S1742706116305232

[25] P. Grzegorz, B. Andrzej, K. Greet, M. Maarten, V. B. Simon, S. Jan, W. Martine, Surface modification of ti6al4v open porous structures produced by additive manufacturing, Advanced Engineering Materials 14 (6) 363-370. arXiv: https://onlinelibrary.wiley.com/doi/pdf/10.1002/adem.201100344, doi:10.1002/adem.201100344.

URL https://onlinelibrary.wiley.com/doi/abs/10.1002/adem. 201100344

[26] V. Urlea, V. Brailovski, Electropolishing and electropolishing-related allowances for powder bed selectively lasermelted ti-6al-4v alloy components, Journal of Materials Processing Technology 242 (2017) 1 - 11 . doi:https: //doi.org/10.1016/j.jmatprotec.2016.11.014.

URL http://www.sciencedirect.com/science/article/pii/S0924013616303958

[27] M. Benedetti, E. Torresani, M. Leoni, V. Fontanari, M. Bandini, C. Pederzolli, C. Potrich, The effect of post-sintering treatments on the fatigue and biological behavior of ti-6al-4v eli parts made by selective laser melting, Journal of the 
Mechanical Behavior of Biomedical Materials 71 (2017) 295 -306. doi:https://doi.org/10.1016/j.jmbbm.2017. 03.024

URL http://www.sciencedirect.com/science/article/pii/S175161611730139X

[28] F. Calignano, D. Manfredi, E. P. Ambrosio, L. Iuliano, P. Fino, Influence of process parameters on surface roughness of aluminum parts produced by dmls, The International Journal of Advanced Manufacturing Technology 67 (9) (2013) 2743-2751. doi:10.1007/s00170-012-4688-9.

URL https://doi.org/10.1007/s00170-012-4688-9

[29] N. Mohammadian, S. Turenne, V. Brailovski, Surface finish control of additively-manufactured inconel 625 components using combined chemical-abrasive flow polishing, Journal of Materials Processing Technology 252 (2018) 728 738. doi:https://doi.org/10.1016/j.jmatprotec.2017.10.020.

URL http://www.sciencedirect.com/science/article/pii/S0924013617304697

[30] M. Ashby, The properties of foams and lattices, Philosophical Transactions of the Royal Society of London A: Mathematical, Physical and Engineering Sciences 364 (1838) (2006) 15-30. arXiv:http://rsta. royalsocietypublishing.org/content/364/1838/15.full.pdf, doi:10.1098/rsta.2005.1678.

URL http://rsta.royalsocietypublishing.org/content/364/1838/15

[31] L. Huynh, J. Rotella, M. D. Sangid, Fatigue behavior of in718 microtrusses produced via additive manufacturing, Materials \& Design 105 (2016) 278 - 289. doi:https://doi.org/10.1016/j.matdes.2016.05.032.

URL http://www.sciencedirect.com/science/article/pii/S0264127516306335

[32] T. Tancogne-Dejean, A. B. Spierings, D. Mohr, Additively-manufactured metallic micro-lattice materials for high specific energy absorption under static and dynamic loading, Acta Materialia 116 (2016) 14 - 28. doi:https: //doi.org/10.1016/j.actamat.2016.05.054.

URL http://www.sciencedirect.com/science/article/pii/S1359645416304153

[33] K. Lietaert, A. Cutolo, D. Boey, B. Van Hooreweder, Fatigue life of additively manufactured ti6al4v scaffolds under tension-tension, tension-compression and compression-compression fatigue load, Scientific reports 8 (1) (2018) 4957.

[34] J. Y. Buffiere, E. Maire, J. Adrien, J. P. Masse, E. Boller, In situ experiments with x ray tomography: an attractive tool for experimental mechanics, Experimental Mechanics 50 (3) (2010) 289-305. doi:10.1007/s11340-010-9333-7. URL https://doi.org/10.1007/s11340-010-9333-7 
[35] M. Suard, G. Martin, P. Lhuissier, R. Dendievel, F. Vignat, J.-J. Blandin, F. Villeneuve, Mechanical equivalent diameter of single struts for the stiffness prediction of lattice structures produced by electron beam melting, Additive Manufacturing 8 (2015) 124 - 131. doi:http://dx.doi.org/10.1016/j.addma.2015.10.002.

URL http://www.sciencedirect.com/science/article/pii/S2214860415000524

[36] T. Persenot, G. Martin, R. Dendievel, J.-Y. Buffiere, E. Maire, Enhancing the tensile properties of ebm as-built thin parts: Effect of hip and chemical etching, Materials Characterizationdoi:https://doi.org/10.1016/j.matchar . 2018.01 .035$.

URL http://www.sciencedirect.com/science/article/pii/S1044580317331479

[37] Airbus Industrie Test Method standards, AIRBUS INDUSTRIE, editor, Airbus Industrie, Engineering Directorate, Blagnac cedex, France, 2001, Ch. AITM 1-0011 Constant amplitude fatigue testing of metallic material, pp. 1-24.

[38] Arcam, Documentation from Arcam training level 2, 2013.

[39] A. Yadollahi, N. Shamsaei, Additive manufacturing of fatigue resistant materials: Challenges and opportunities, International Journal of Fatigue 98 (2017) 14-31. doi:https://doi.org/10.1016/j.ijfatigue.2017.01.001. URL http://www.sciencedirect.com/science/article/pii/S0142112317300014

[40] S. Tammas-Williams, H. Zhao, F. Lonard, F. Derguti, I. Todd, P. Prangnell, Xct analysis of the influence of melt strategies on defect population in ti6al4v components manufactured by selective electron beam melting, Materials Characterization 102 (2015) 47 -61. doi:http://dx.doi.org/10.1016/j.matchar.2015.02.008.

URL http://www.sciencedirect.com/science/article/pii/S104458031500039X

[41] C. Körner, A. Bauerei, E. Attar, Fundamental consolidation mechanisms during selective beam melting of powders, Modelling and Simulation in Materials Science and Engineering 21 (8) (2013) 085011.

URL http://stacks.iop.org/0965-0393/21/i=8/a=085011

[42] H. Galarraga, D. A. Lados, R. R. Dehoff, M. M. Kirka, P. Nandwana, Effects of the microstructure and porosity on properties of Ti-6Al-4V ELI alloy fabricated by electron beam melting (EBM), Additive Manufacturing 10 (2016) 47-57. arXiv:1510.09070, doi:10.1016/j.addma.2016.02.003.

URL http://dx.doi.org/10.1016/j.addma.2016.02.003

[43] L. Facchini, E. Magalini, P. Robotti, A. Molinari, Microstructure and mechanical properties of ti6al4v produced by electron beam melting of prealloyed powders, Rapid Prototyping Journal 15 (3) (2009) 171-178. arXiv:https: 
//doi.org/10.1108/13552540910960262, doi:10.1108/13552540910960262.

URL https://doi.org/10.1108/13552540910960262

[44] X. Zhao, S. Li, M. Zhang, Y. Liu, T. B. Sercombe, S. Wang, Y. Hao, R. Yang, L. E. Murr, Comparison of the microstructures and mechanical properties of ti6al4v fabricated by selective laser melting and electron beam melting, Materials \& Design 95 (2016) 21 - 31. doi:https://doi.org/10.1016/j.matdes.2015.12.135.

URL http://www.sciencedirect.com/science/article/pii/S0264127515309928

[45] H. Gong, K. Rafi, H. Gu, G. J. Ram, T. Starr, B. Stucker, Influence of defects on mechanical properties of ti6al4v components produced by selective laser melting and electron beam melting, Materials \& Design 86 (2015) 545 - 554 . doi:https://doi.org/10.1016/j.matdes.2015.07.147.

URL http://www.sciencedirect.com/science/article/pii/S0264127515302161

[46] S. Leuders, T. Lieneke, S. Lammers, T. Tröster, T. Niendorf, On the fatigue properties of metals manufactured by selective laser melting the role of ductility, Journal of Materials Research 29 (17) (2014) 19111919. doi:10.1557/ jmr.2014.157.

[47] G. Kasperovich, J. Hausmann, Improvement of fatigue resistance and ductility of tial6v4 processed by selective laser melting, Journal of Materials Processing Technology 220 (2015) 202 - 214. doi:https://doi.org/10.1016/j . jmatprotec.2015.01.025.

URL http://www.sciencedirect.com/science/article/pii/S0924013615000278

[48] J. Schijve, Fatigue of structures and materials, Springer Science \& Business Media, 2001.

[49] S. Tammas-Williams, P. Withers, I. Todd, P. Prangnell, The influence of porosity on fatigue crack initiation in additively manufactured titanium components, Scientific reports 7 (1) (2017) 7308.

[50] A. Borbély, H. Mughrabi, G. Eisenmeier, H. Höppel, A finite element modelling study of strain localization in the vicinity of near-surface cavities as a cause of subsurface fatigue crack initiation, International Journal of Fracture 115 (3) (2002) 227-232. doi:10.1023/A:1016350528652.

URL https://doi.org/10.1023/A : 1016350528652

[51] H. Kitagawa, S. Takahashi, Applicability of fracture mechanics to very small cracks or the cracks in the early stage, in: Second International Conference on Mechanical Behavior of Materials. ASM, Metals Park, Ohio. 1976, 627-631, 1976. 
[52] S. Beretta, S. Romano, A comparison of fatigue strength sensitivity to defects for materials manufactured by am or traditional processes, International Journal of Fatigue 94 (2017) 178 - 191, fatigue and Fracture Behavior of Additive Manufactured Parts. doi:https://doi.org/10.1016/j.ijfatigue.2016.06.020.

URL http://www.sciencedirect.com/science/article/pii/S0142112316301645

[53] A. Rotella, Y. Nadot, M. Piellard, R. Augustin, Influence of natural defects on the fatigue limit of a cast al-si alloy, Procedia Structural Integrity 7 (2017) 513 - 520, 3rd International Symposium on Fatigue Design and Material Defects, FDMD 2017. doi:https://doi.org/10.1016/j.prostr.2017.11.120.

URL http://www.sciencedirect.com/science/article/pii/S2452321617304778

[54] M. E. Haddad, T. Topper, K. Smith, Prediction of non propagating cracks, Engineering Fracture Mechanics 11 (3) (1979) 573 - 584. doi:https://doi.org/10.1016/0013-7944(79)90081-X.

URL http://www.sciencedirect.com/science/article/pii/001379447990081X

[55] J. Kruzic, R. Ritchie, Kitagawa-takahashi diagrams define the limiting conditions for cyclic fatigue failure in human dentin, Journal of Biomedical Materials Research Part A 79 (3) (2006) 747-751.

[56] M. Seifi, M. Dahar, R. Aman, O. Harrysson, J. Beuth, J. J. Lewandowski, Evaluation of orientation dependence of fracture toughness and fatigue crack propagation behavior of as-deposited arcam ebm ti-6al-4v, JOM 67 (3) (2015) 597-607. doi:10.1007/s11837-015-1298-7.

URL https://doi.org/10.1007/s11837-015-1298-7

[57] M. Seifi, A. Salem, D. Satko, J. Shaffer, J. J. Lewandowski, Defect distribution and microstructure heterogeneity effects on fracture resistance and fatigue behavior of ebm ti6al4v, International Journal of Fatigue 94 (2017) 263 287, fatigue and Fracture Behavior of Additive Manufactured Parts. doi:https://doi.org/10.1016/j.ijfatigue. 2016.06 .001

URL http://www.sciencedirect.com/science/article/pii/S0142112316301451

[58] D. Greitemeier, F. Palm, F. Syassen, T. Melz, Fatigue performance of additive manufactured tial6v4 using electron and laser beam melting, International Journal of Fatigue 94 (2017) 211 - 217, fatigue and Fracture Behavior of Additive Manufactured Parts. doi:https://doi.org/10.1016/j.ijfatigue.2016.05.001.

URL http://www.sciencedirect.com/science/article/pii/S0142112316300871

[59] Y. Zhai, H. Galarraga, D. A. Lados, Microstructure, static properties, and fatigue crack growth mechanisms in ti-6al4v fabricated by additive manufacturing: Lens and ebm, Engineering Failure Analysis 69 (2016) 3-14, special issue on 
the International Conference on Structural Integrity. doi :https ://doi .org/10.1016/j .engfailanal.2016.05.036. URL http://www.sciencedirect.com/science/article/pii/S1350630716303752

[60] D. Greitemeier, C. Dalle Donne, F. Syassen, J. Eufinger, T. Melz, Effect of surface roughness on fatigue performance of additive manufactured ti-6al-4v, Materials Science and Technology 32 (7) (2016) 629-634.

[61] P. Collins, D. Brice, P. Samimi, I. Ghamarian, H. Fraser, Microstructural control of additively manufactured metallic materials, Annual Review of Materials Research 46 (2016) 63-91.

[62] Y. Murakami, Analysis of stress intensity factors of modes i, ii and iii for inclined surface cracks of arbitrary shape, Engineering Fracture Mechanics 22 (1) (1985) 101 - 114. doi:https://doi.org/10.1016/0013-7944(85)90163-8. URL http://www.sciencedirect.com/science/article/pii/0013794485901638

[63] M. Ciavarella, F. Monno, On the possible generalizations of the kitagawatakahashi diagram and of the el haddad equation to finite life, International Journal of Fatigue 28 (12) (2006) 1826 - 1837. doi:https://doi.org/10.1016/ j.ijfatigue.2005.12.001.

URL http://www.sciencedirect.com/science/article/pii/S0142112306000120

[64] P. Lorenzino, S. Okazaki, H. Matsunaga, Y. Murakami, Effect of small defect orientation on fatigue limit of carbon steels, Fatigue \& Fracture of Engineering Materials \& Structures 38 (9) (2015) 1076-1086.

[65] S. Romano, A. Brando, J. Gumpinger, M. Gschweitl, S. Beretta, Qualification of am parts: Extreme value statistics applied to tomographic measurements, Materials \& Design 131 (2017) 32 - 48. doi:https://doi.org/10.1016/j. matdes.2017.05.091.

URL http://www.sciencedirect.com/science/article/pii/S0264127517305737 
a)

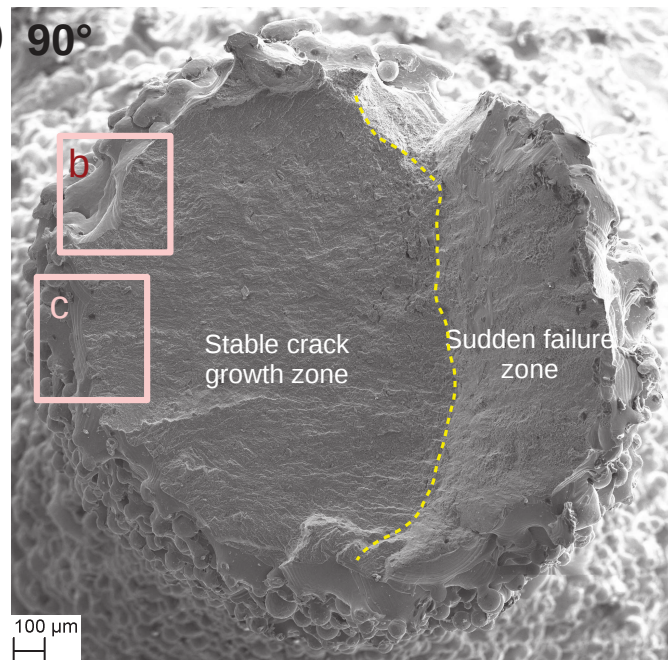

d)
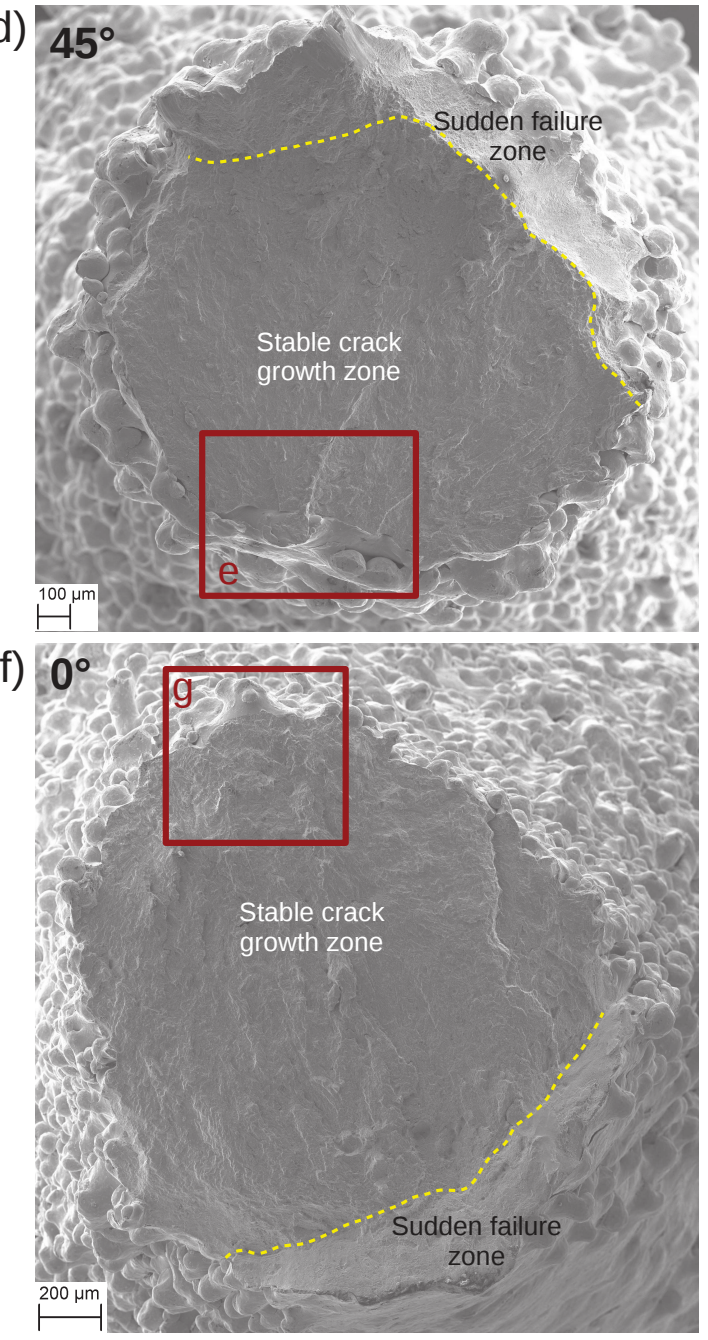

Figure 3: SEM micrographs of the fracture surfaces of as-built EBM fatigue samples. (a,d,f) Fracture surfaces showing the stable crack growth and sudden failure zones of $90^{\circ}, 45^{\circ}$ and $0^{\circ}$ samples respectively. (b,c,e,g) Higher magnification images showing the crack inititiation sites. b)

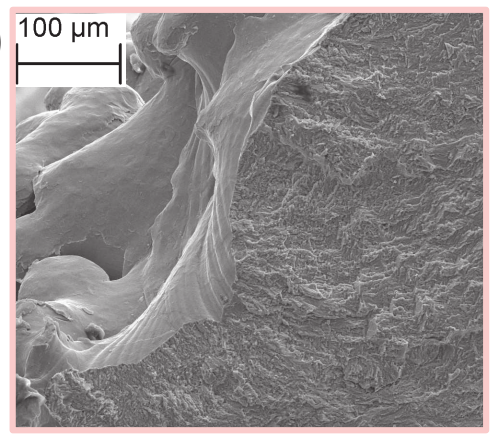

c)

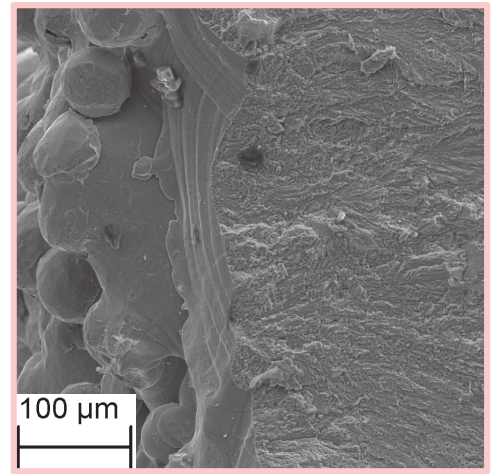

e)
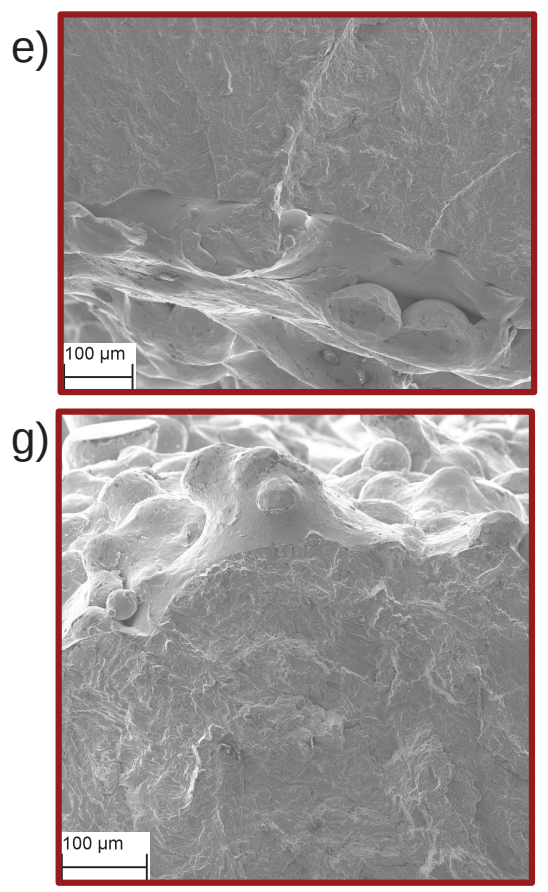
a)

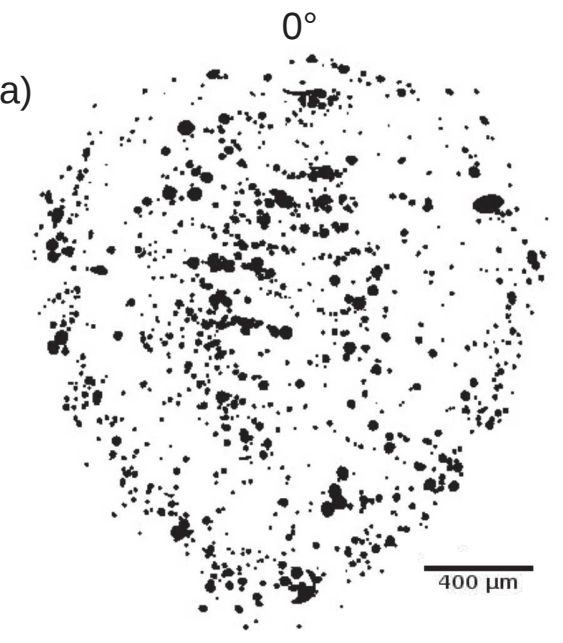

$45^{\circ}$

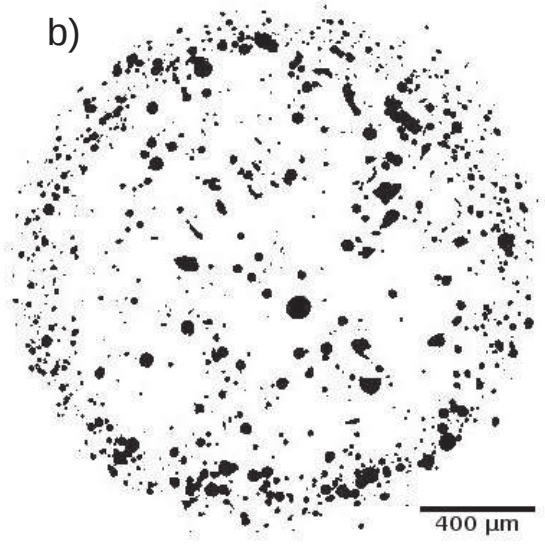

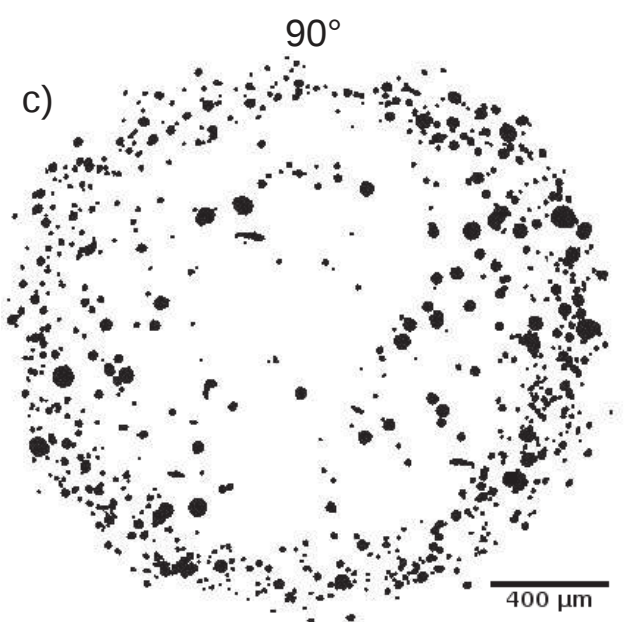

Figure 4: Projected views of all the internal pores within the gauge length of three samples (10mm) as detected by X-ray lab tomography (2.5 $\mu \mathrm{m}$ voxel size). (a) $0^{\circ}$ sample, (b) $45^{\circ}$ sample and (c) $90^{\circ}$ sample. The corresponding volume fraction pores are respectively $0.035 \%, 0.040 \%$ and $0.025 \%$ for the $0^{\circ}, 45^{\circ}$ and $90^{\circ}$ samples.

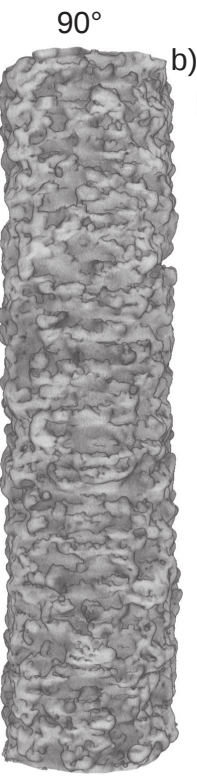

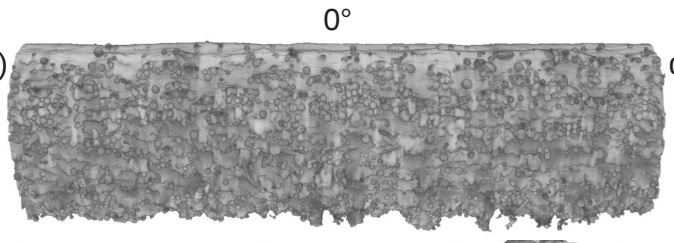

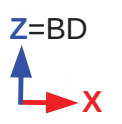

c)

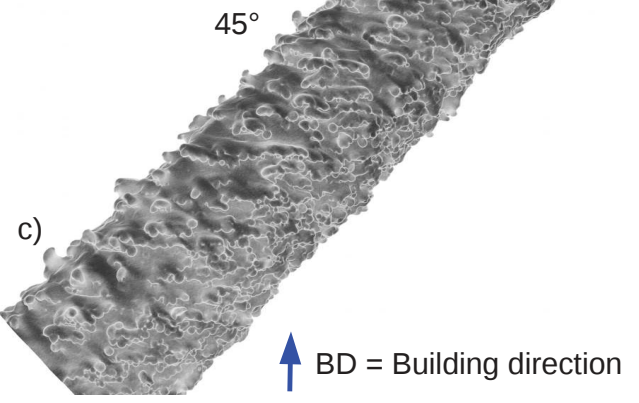

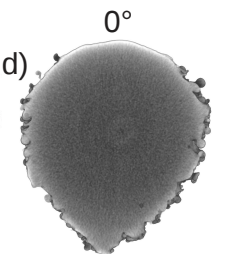

e)

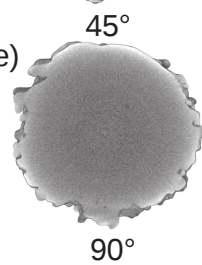

f)

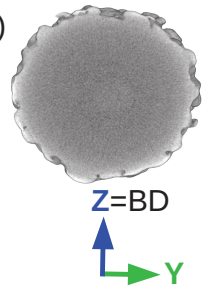

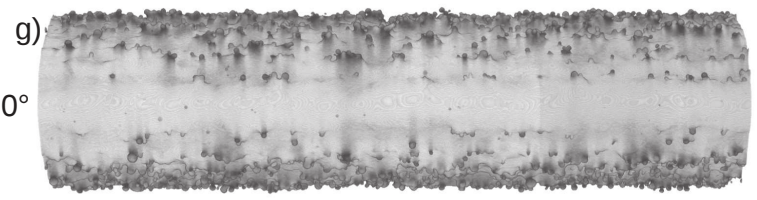
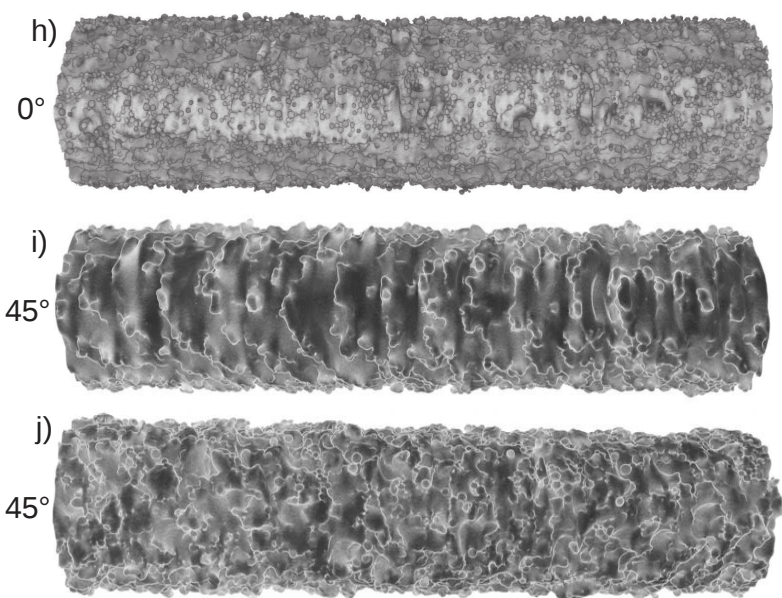

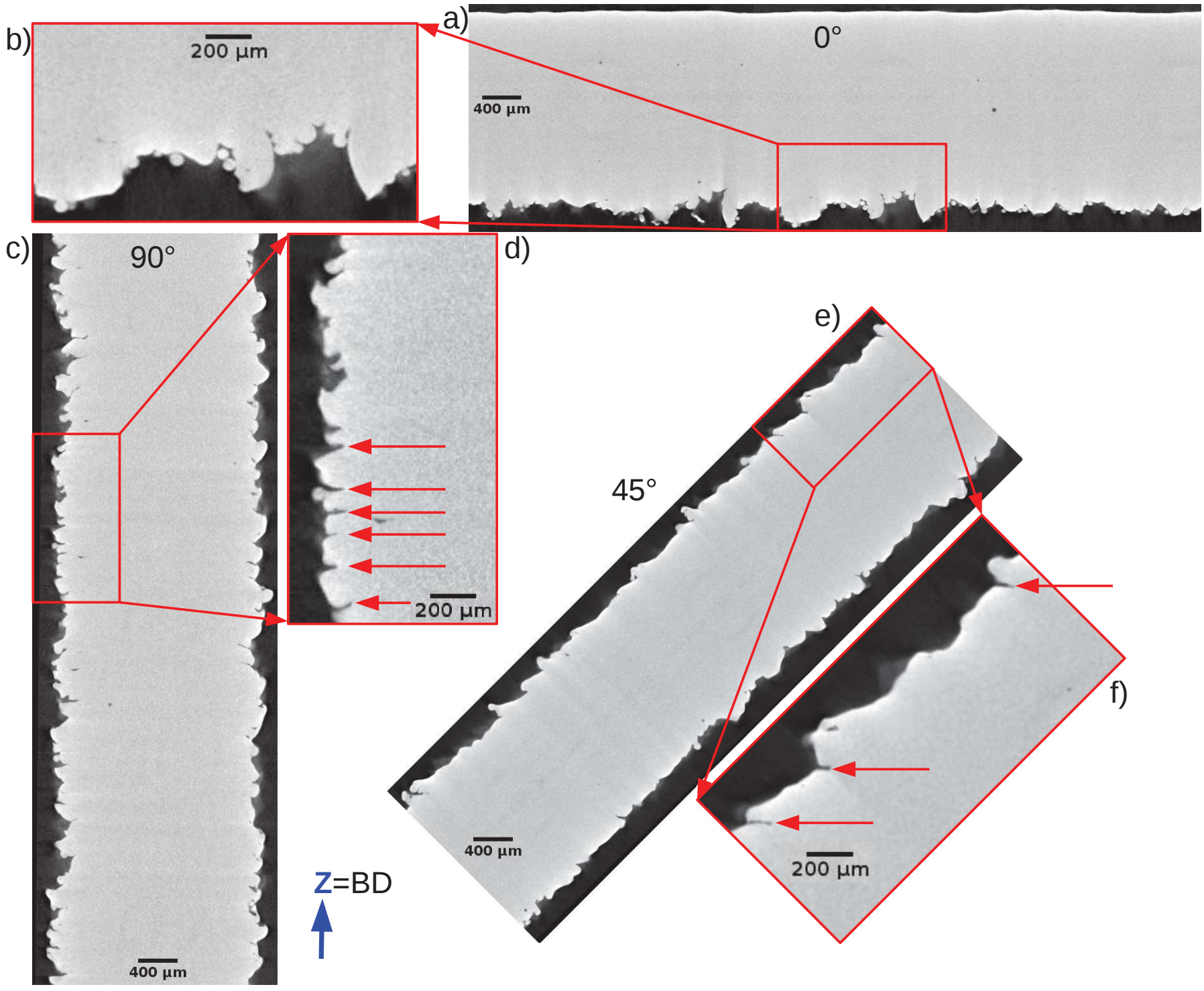

Figure 6: Impact of the build orientation on the surface of the samples gauge length. (a,c,e) Radial slices of samples manufactured respectively at $0^{\circ}, 45^{\circ}$ and $90^{\circ}$. (b,d and f) Magnification around surface defects. The slices are oriented in order to mimic the sample orientation in the build chamber, the building direction being vertical (blue arrow). 


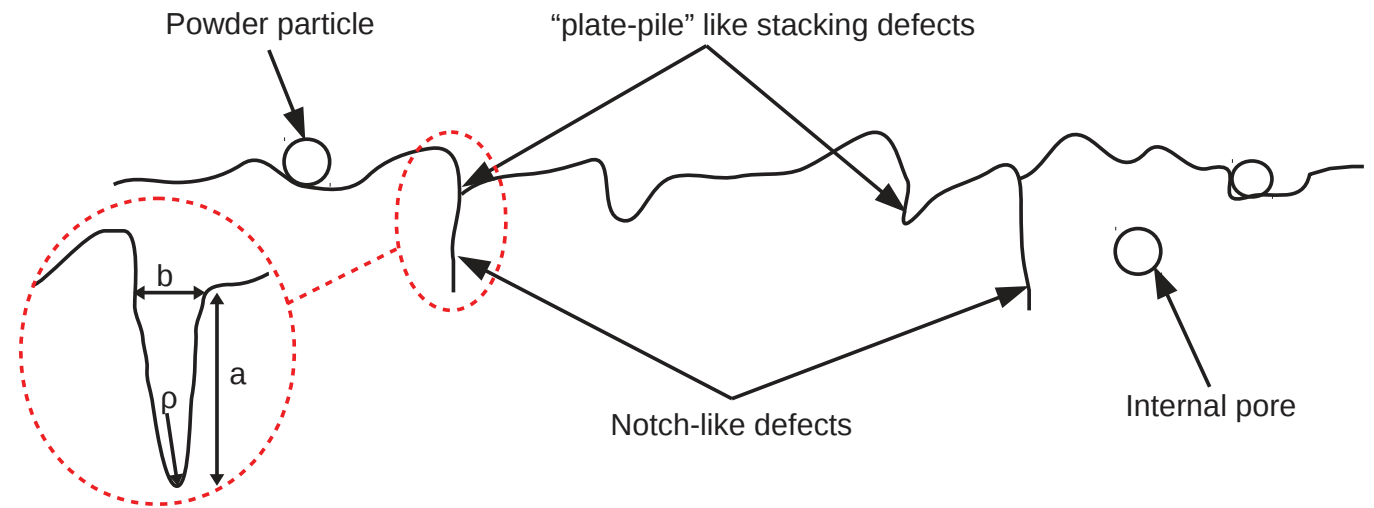

Figure 7: Schematic illustration of the defects that can be found in EBM as-built samples. Geometrical parameters describing a surface notch are also shown. $\mathrm{a}, \mathrm{b}$ and $\rho$ represent respectively the depth of the notch, its thickness and the radius of curvature at its tip.

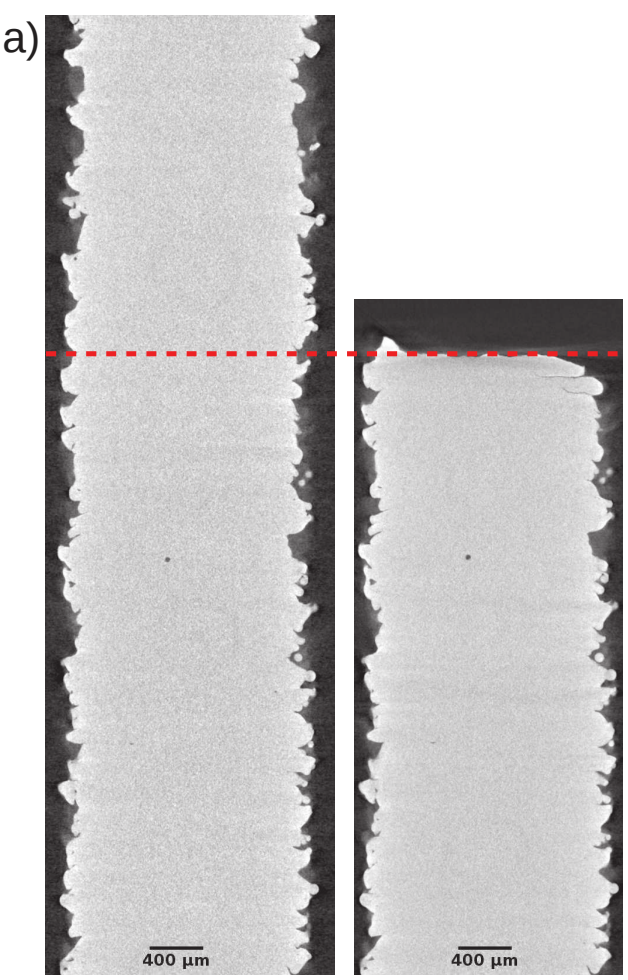

b)

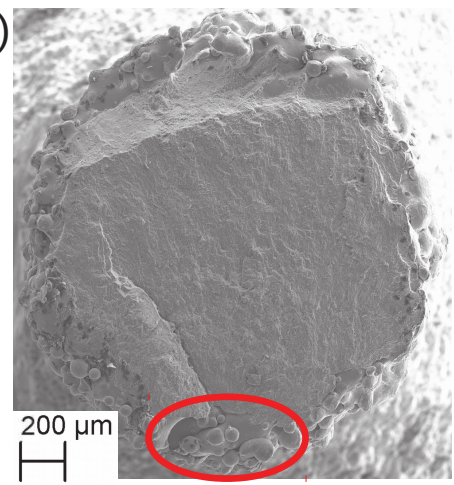

c)

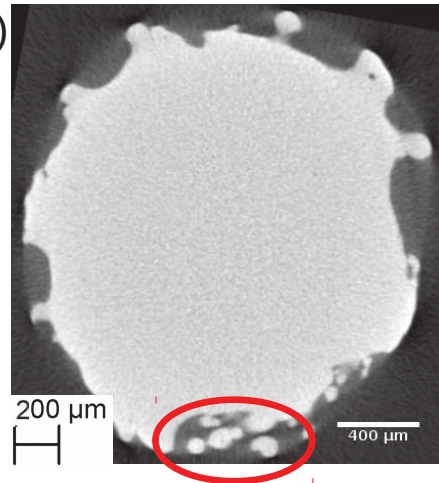

Figure 8: Schematic illustration of the methodology used to identify the defect responsible for the failure of a fatigue sample. (a) Radial slices obtained by X-ray tomography of a sample before and after fatigue failure. Their comparison enables us to identify the critical cross section, i.e. the height in the gauge length at which the failure occurred. (b) SEM observation of the fracture surface of the fatigue sample. (c) Slice view of the critical cross section of the sample before fatigue test. Comparison of (b) and (c) leads to the critical defect identification. 

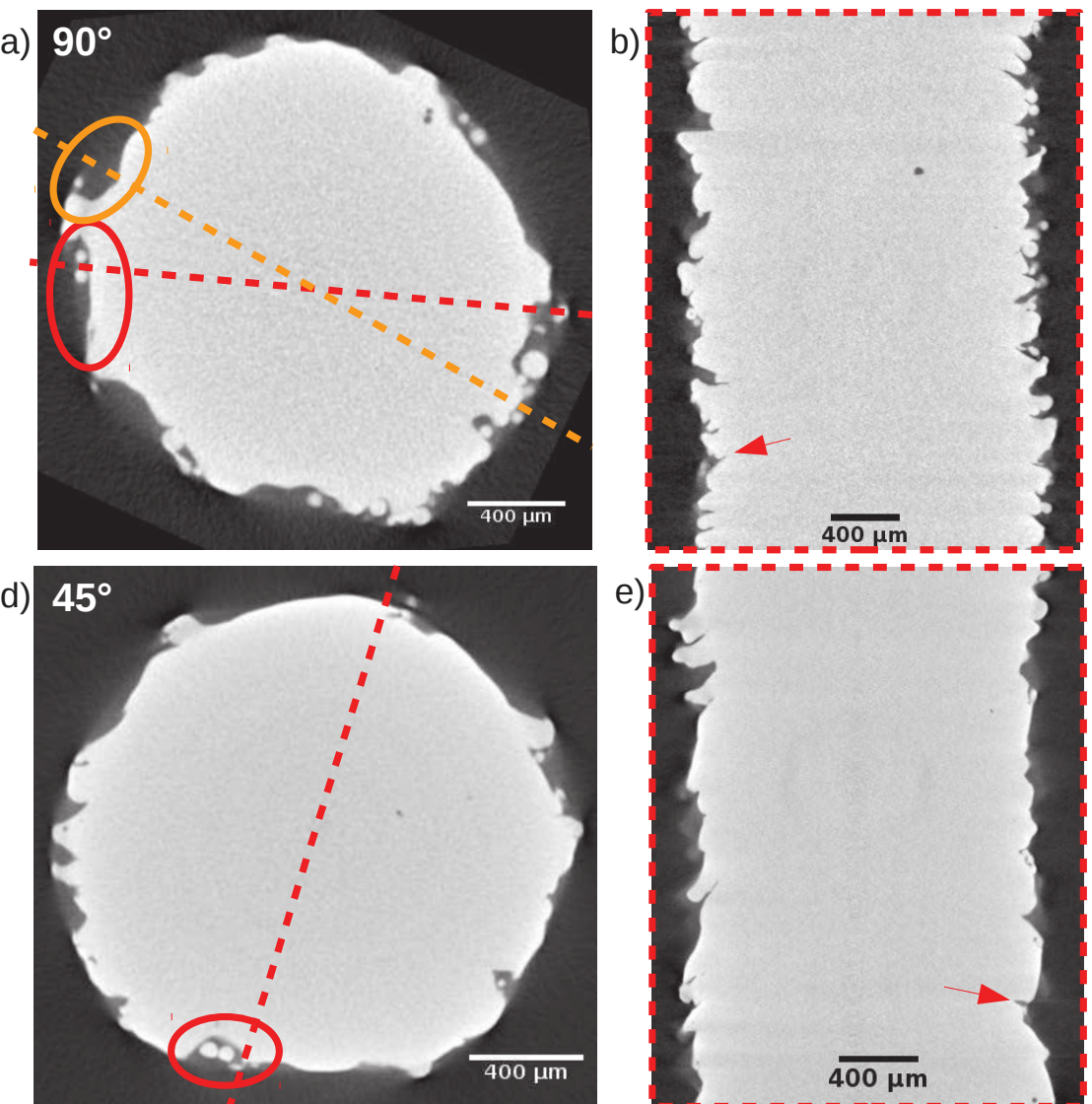

e)

f)
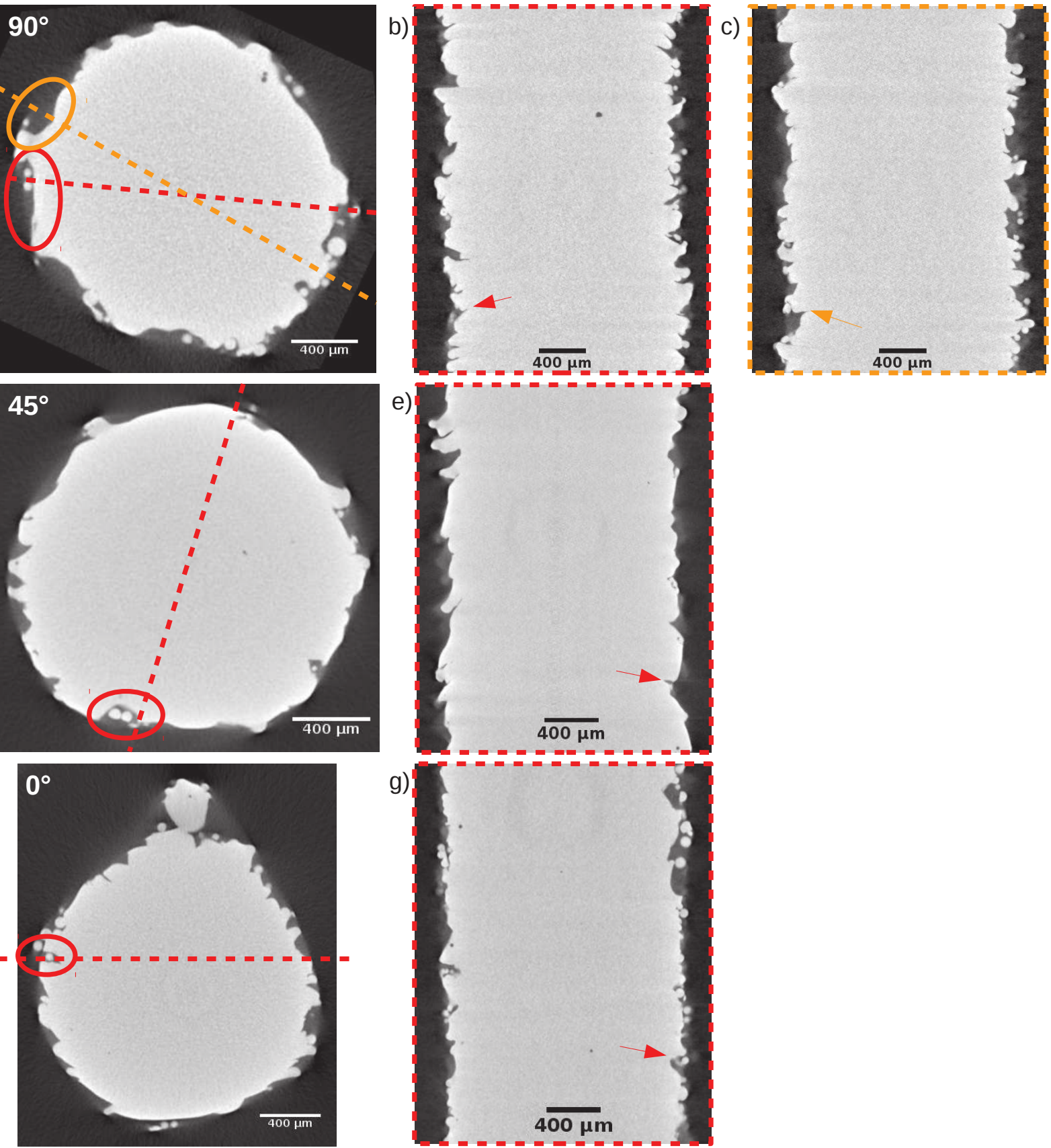

g)

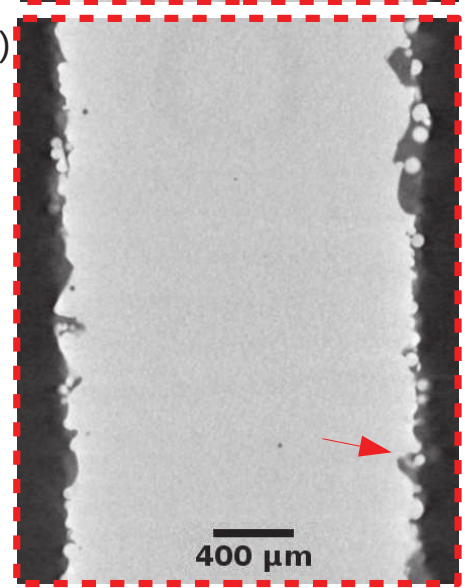

Figure 9: Examples of surface defects responsible for the failure of as-built samples. (a,d,f) Axial slices of critical defects for respectively $90^{\circ}$, $45^{\circ}$ and $0^{\circ}$ samples. (b,c,e,g) Radial slices of critical defects for respectively $90^{\circ}, 45^{\circ}$ and $0^{\circ}$ samples. Arrows and ellipses identify the critical defects. The dotted lines on the axial slices indicate the corresponding radial slices. 


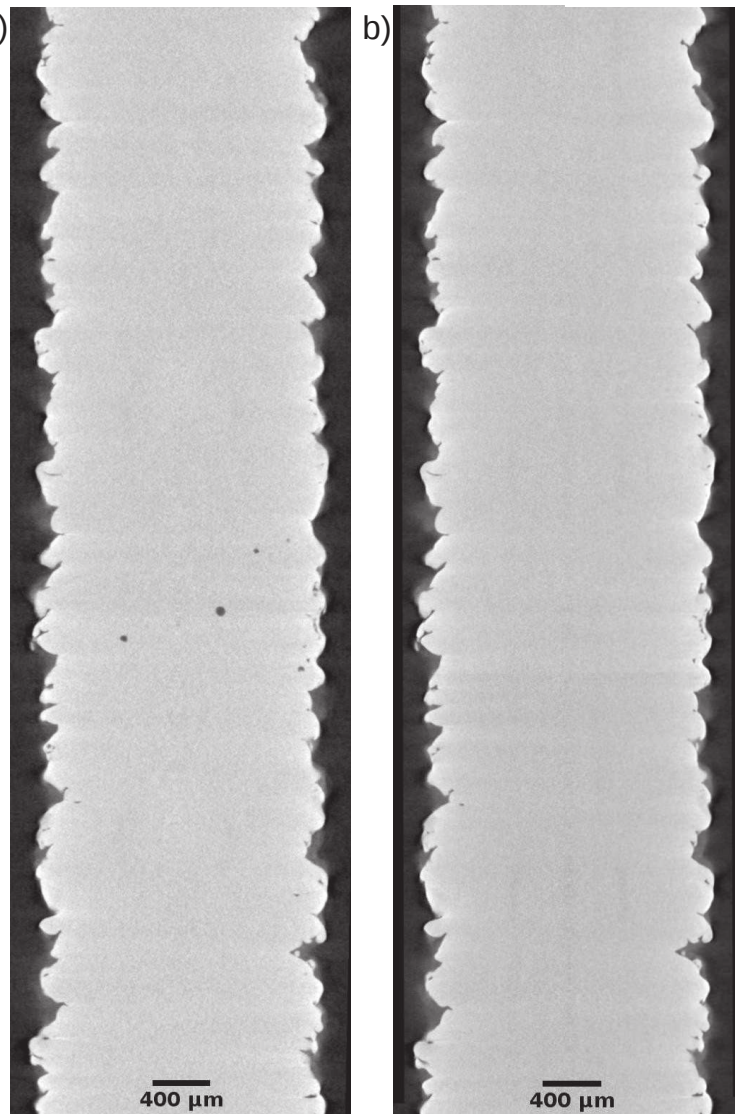

Figure 10: X-ray tomography images showing the same radial slice of a sample gauge length before (a) and after (b) HIP treatment. After HIP, no remaining pores can be detected with a voxel size of $2.5 \mu m$. 

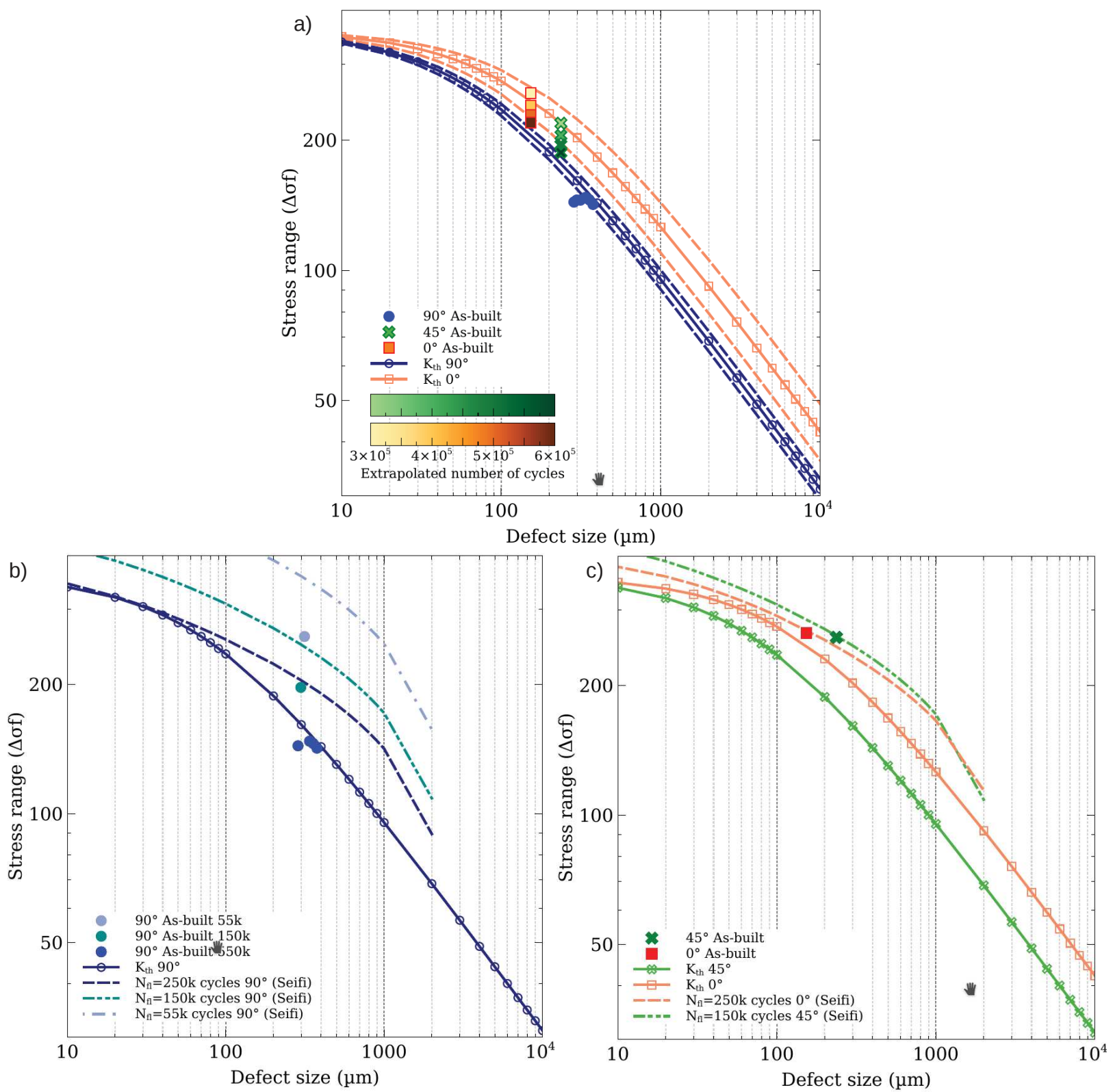

Figure 11: Modified Kitagawa-Takahashi diagrams of EBM Ti-6Al-4V alloy. (a) Method suggested by Beretta and Romano [52]. The blue and red lines correspond respectively to notches perpendicular and parallel to the building direction. The continuous lines were plotted using the average $K_{t h}$ value from the literature while minimum and maximum values were considered for the dotted lines. The blue dots, green crosses and red squares correspond respectively to the $90^{\circ}, 45^{\circ}$ and $0^{\circ}$ samples for which the size of the defect responsible for the failure was measured. Their stress range was extrapolated to larger fatigue lives corresponding to the knee-point of the Wöhler curve. (b) Diagram extended to finite lives following the approach of Ciavarella and Monno [63]. Each curve corresponds to a given number of cycles $N_{f l}$ and relies on the stress amplitude corresponding to $N_{f l}$ as well as a propagation law. The experimental stress range was directly used for the blue dots, green crosses and red squares. 
fig_3d-views v2.pdf

a)

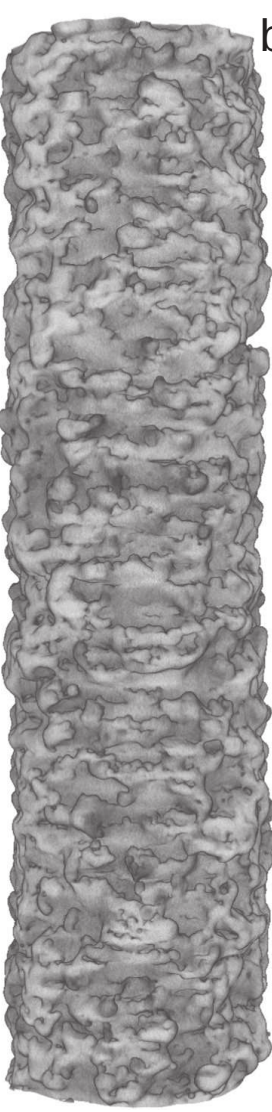

b)

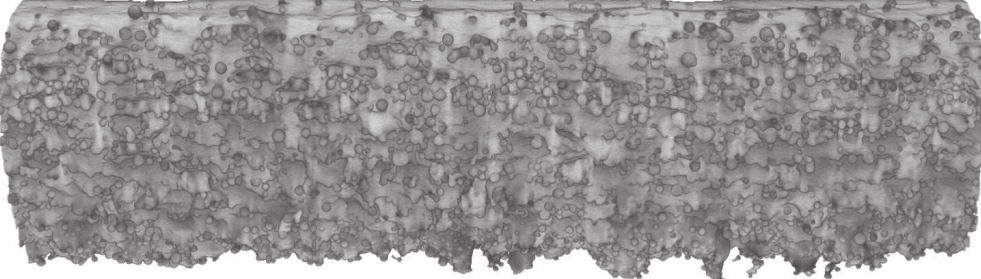

$\mathrm{Z}=\mathrm{BD}$

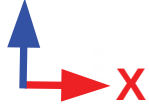

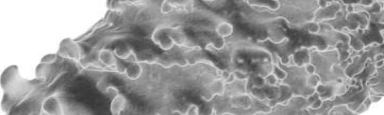

$45^{\circ}$
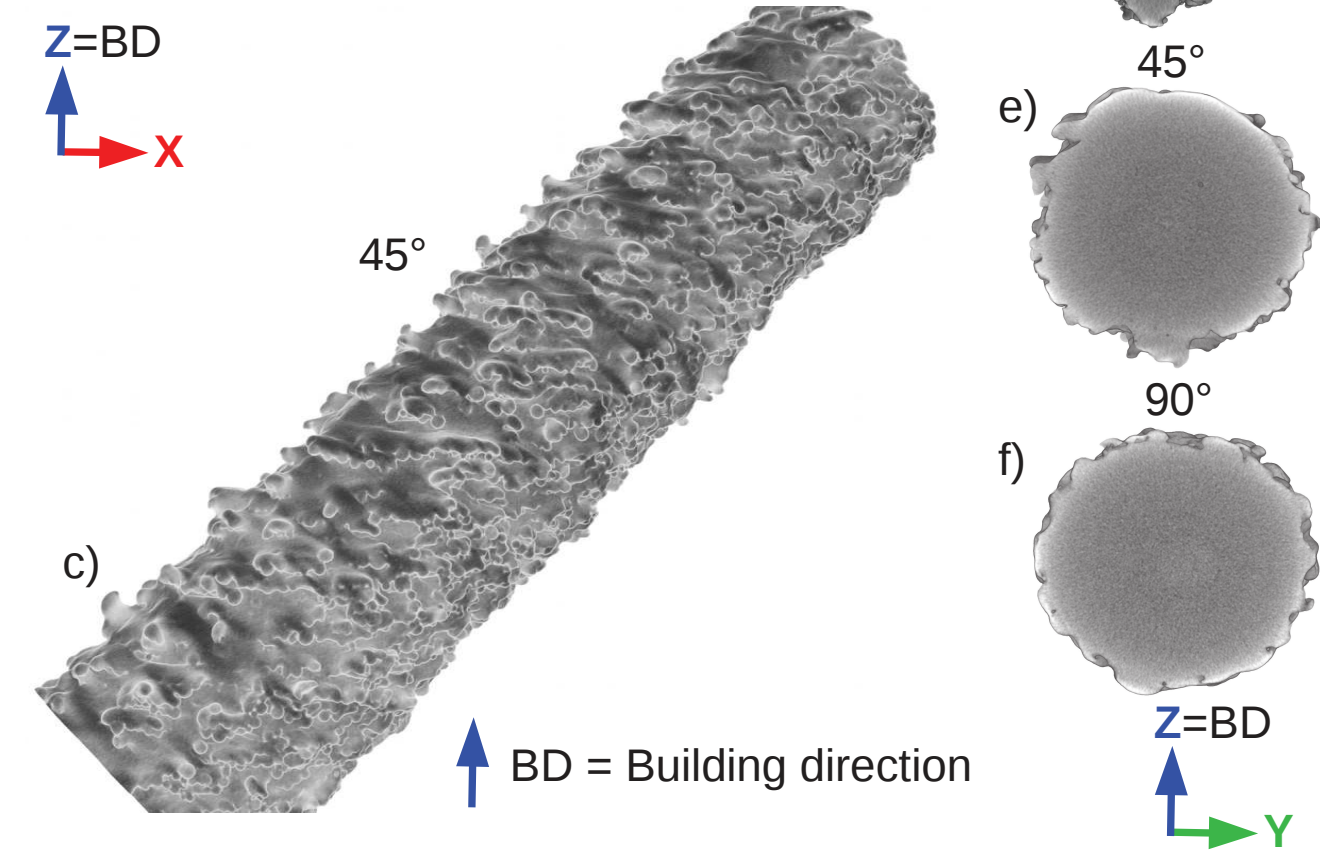

e) g)
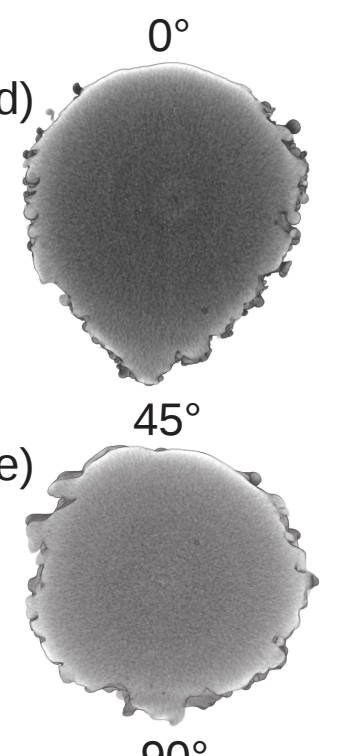

$0^{\circ}$

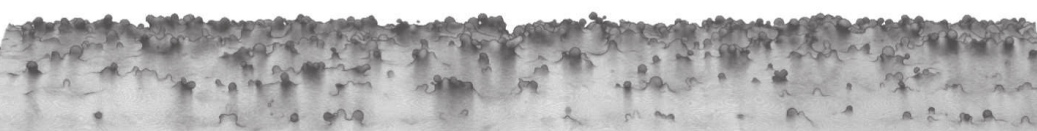

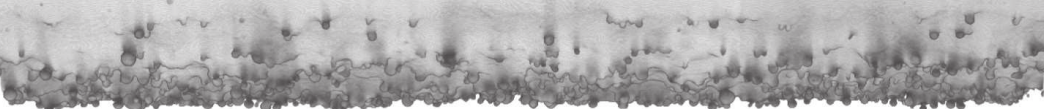

h)

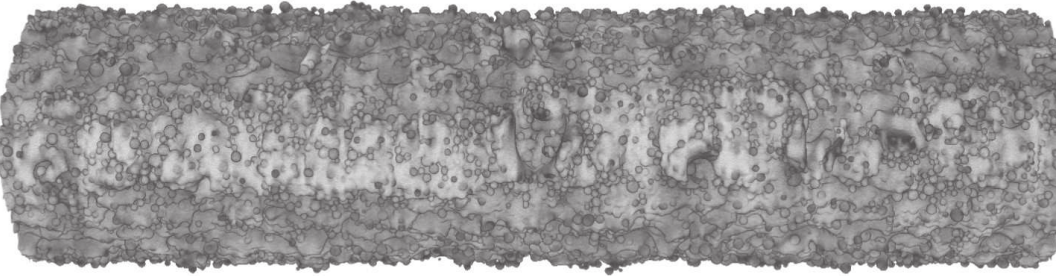

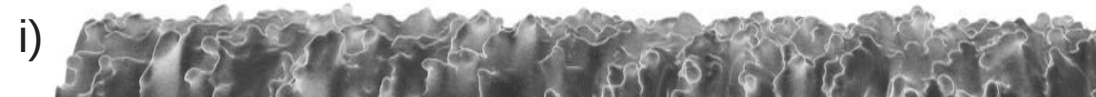
$45^{\circ}$

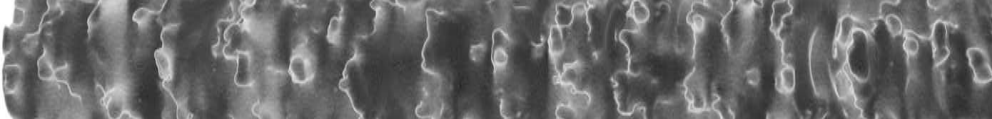
4.

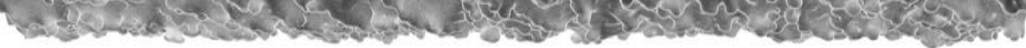

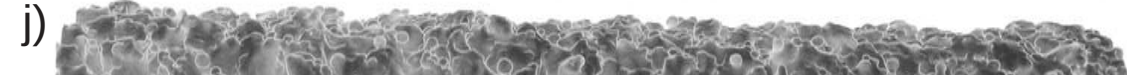

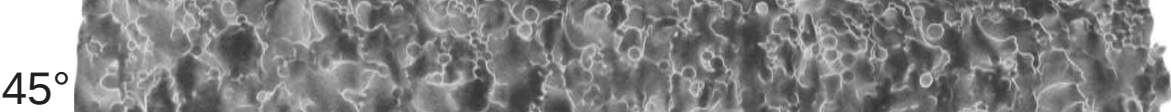
5.

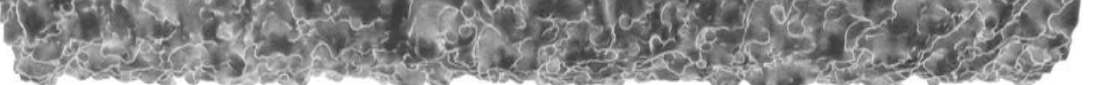




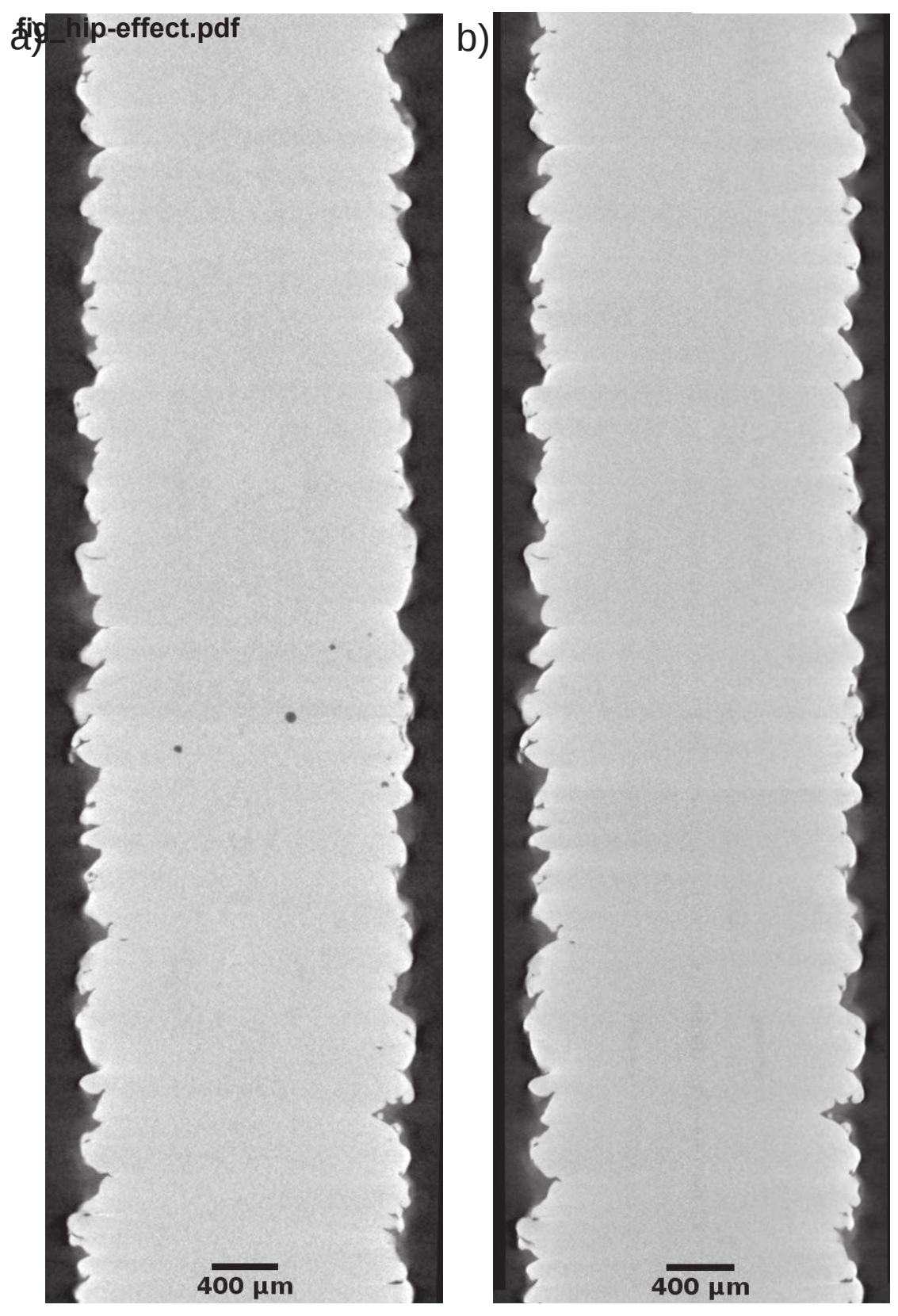



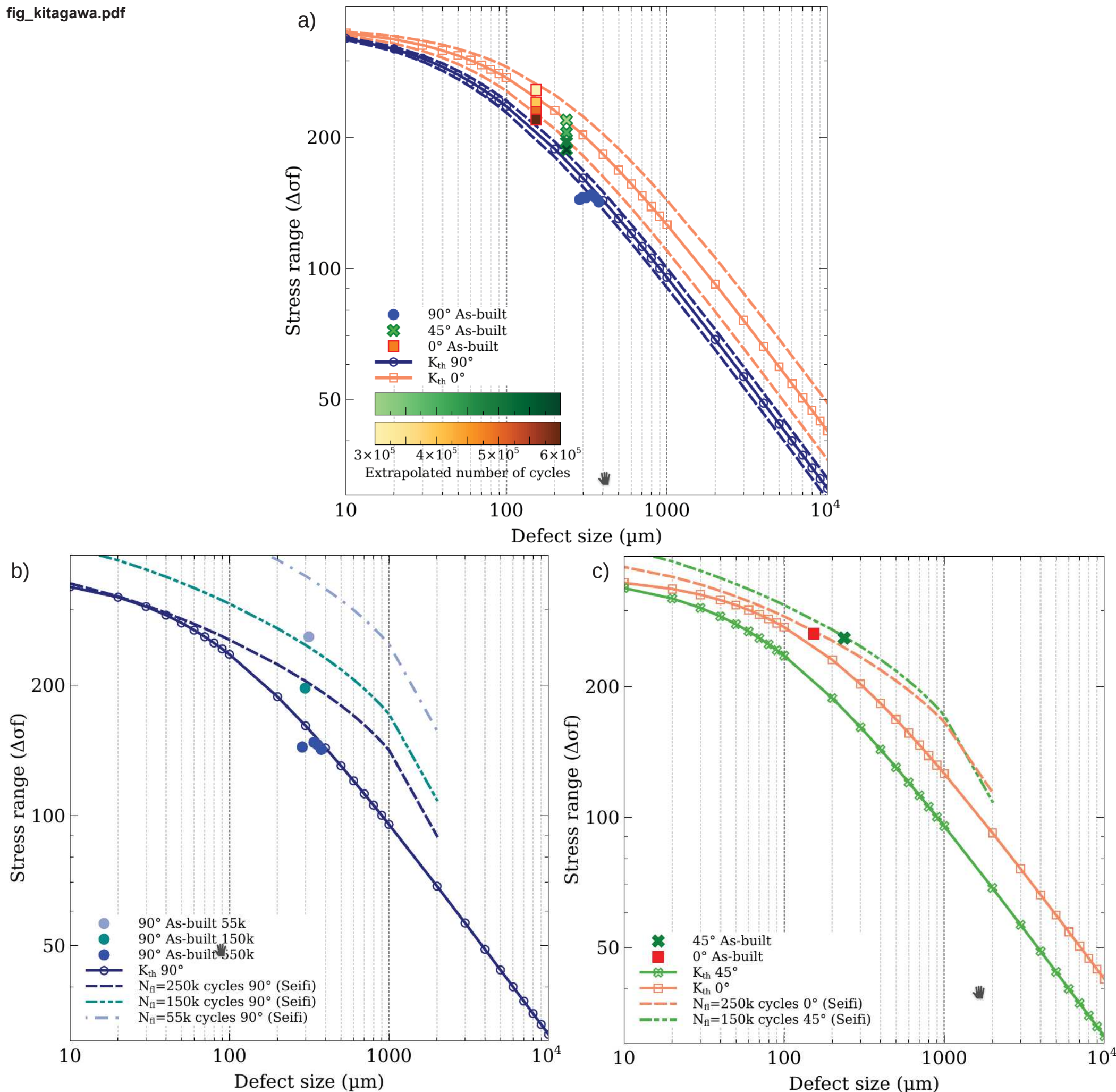


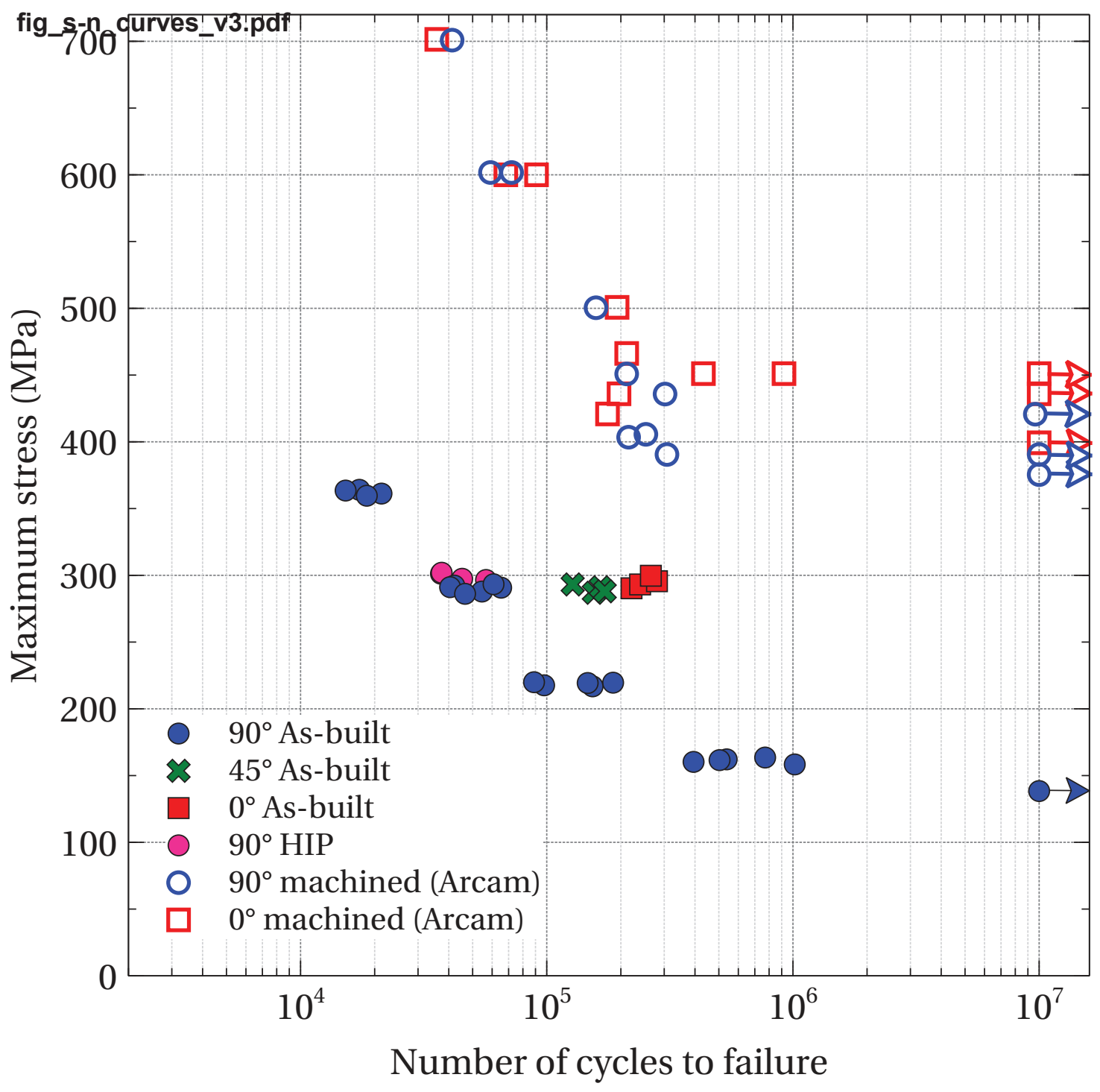




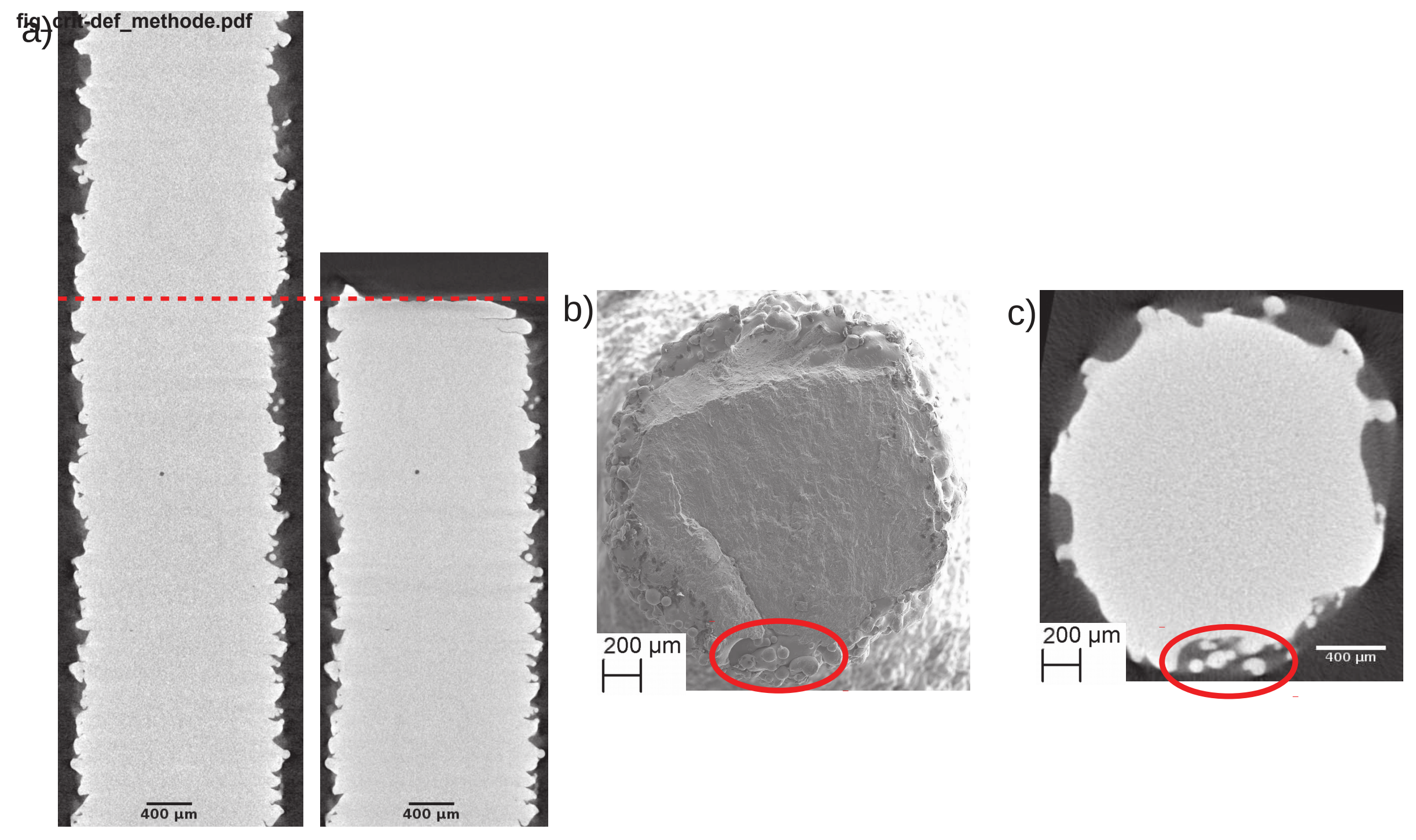




\section{fig $90^{\circ}$}

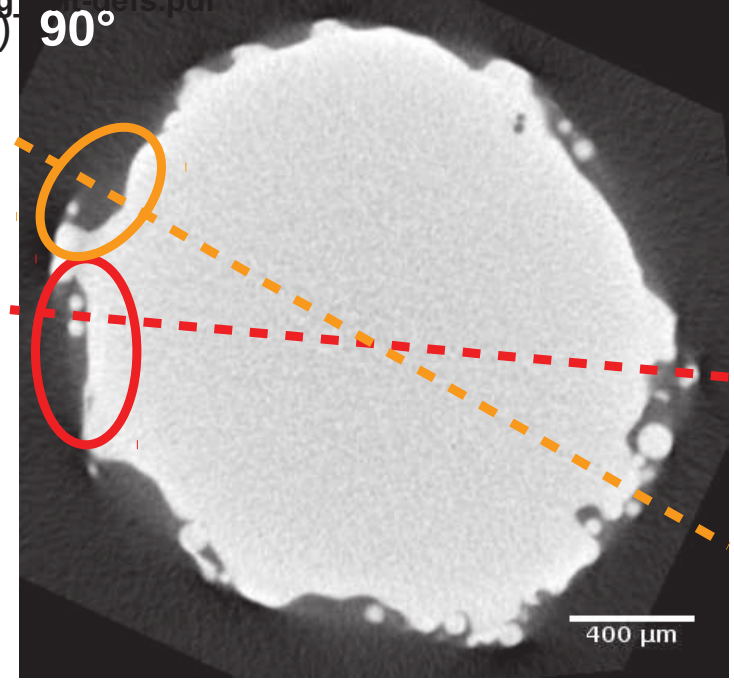

d) $45^{\circ}$

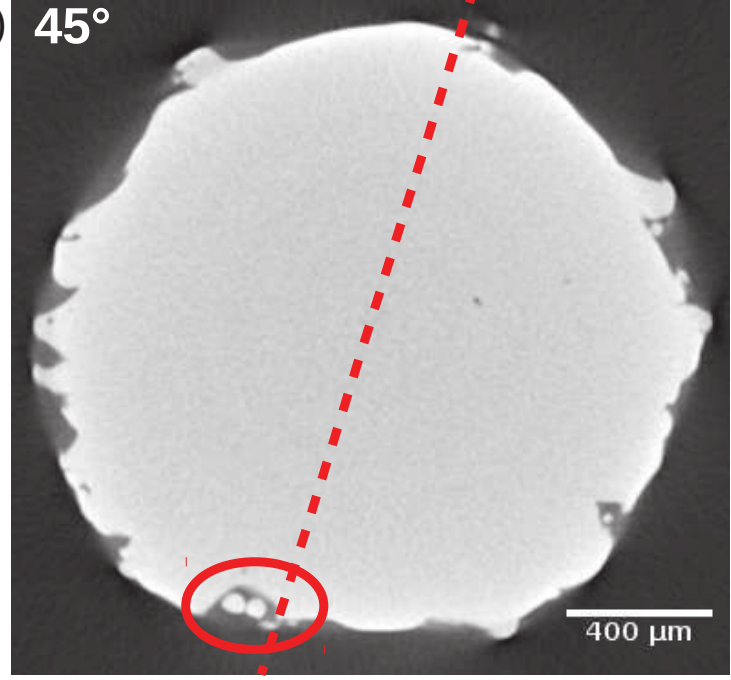

f)

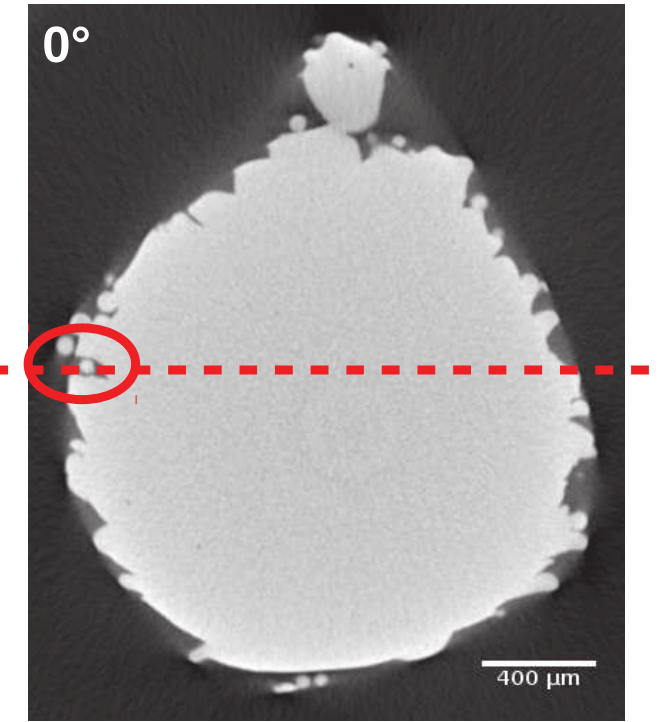

b)

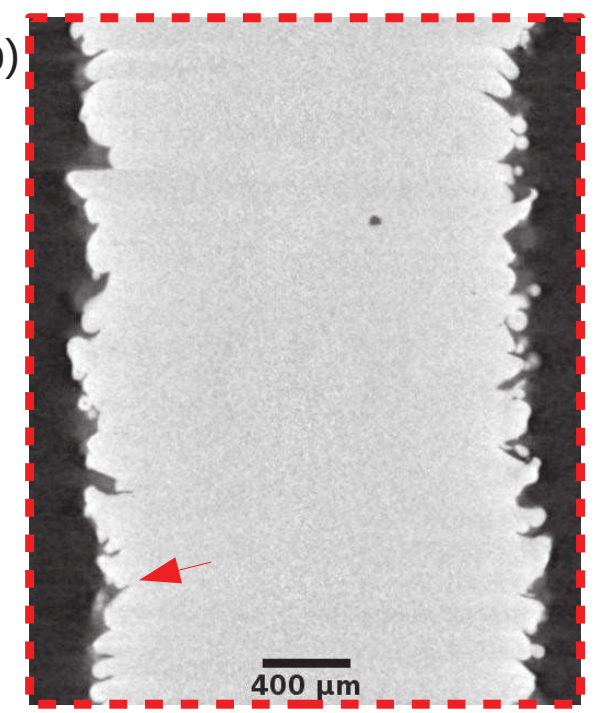

e)

Eva

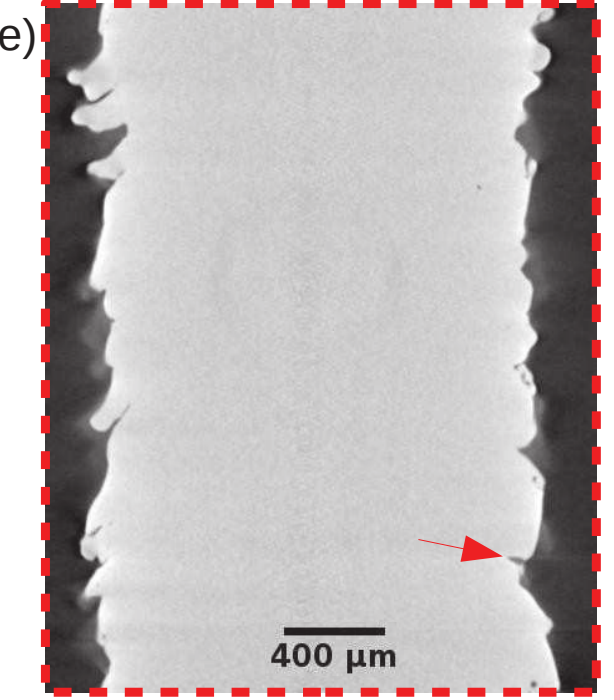

g)

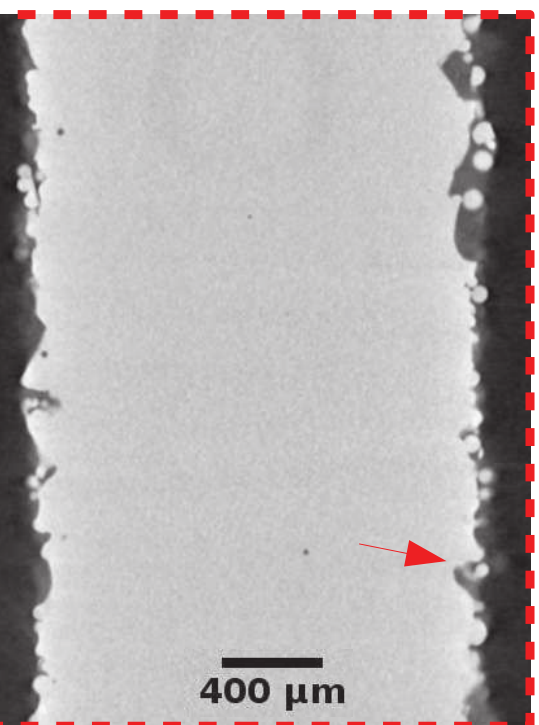

c)

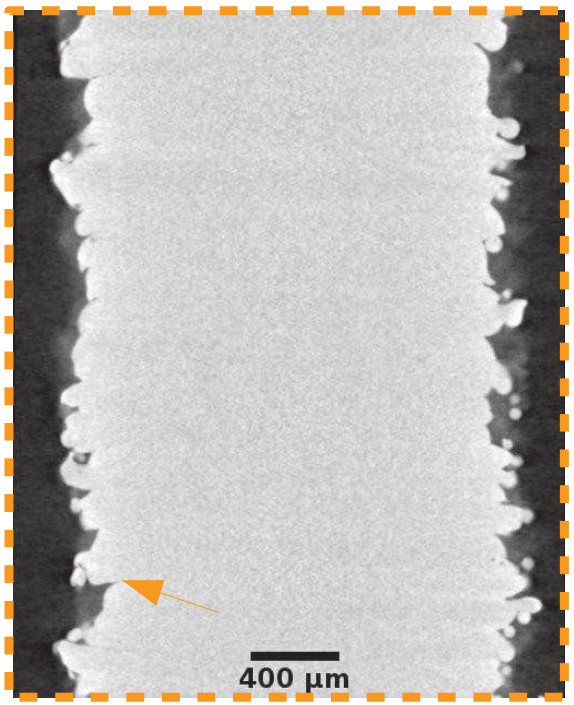


fig-frac-surf-v2.pdf , $90^{\circ}$, ab a

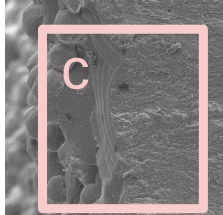

Stable crack growth zone

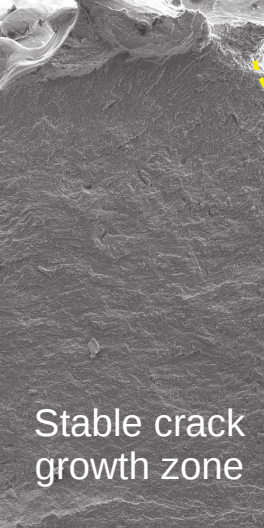

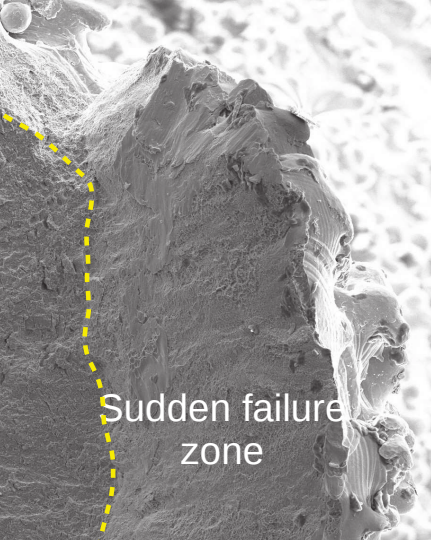
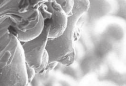
ta) 280.94

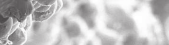

Pin -6itest
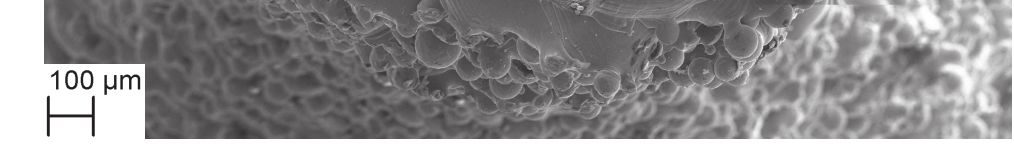

d) $45^{\circ}$

Stable crack

growth zone

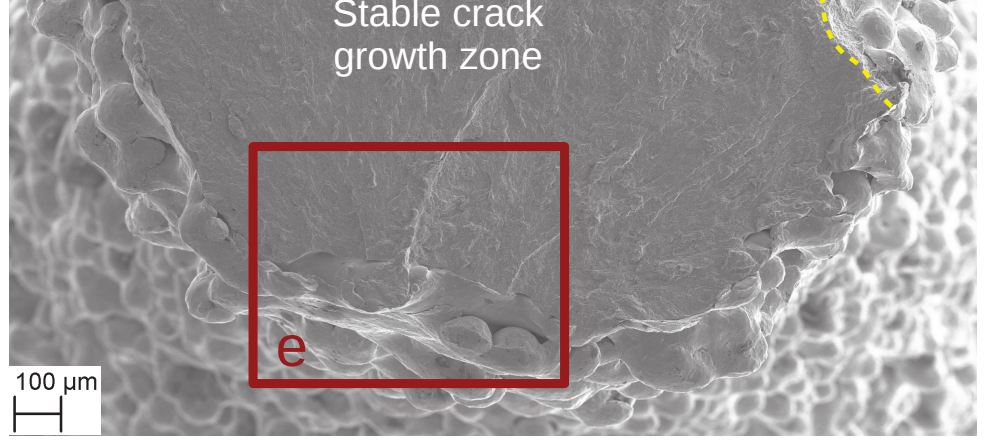

f)

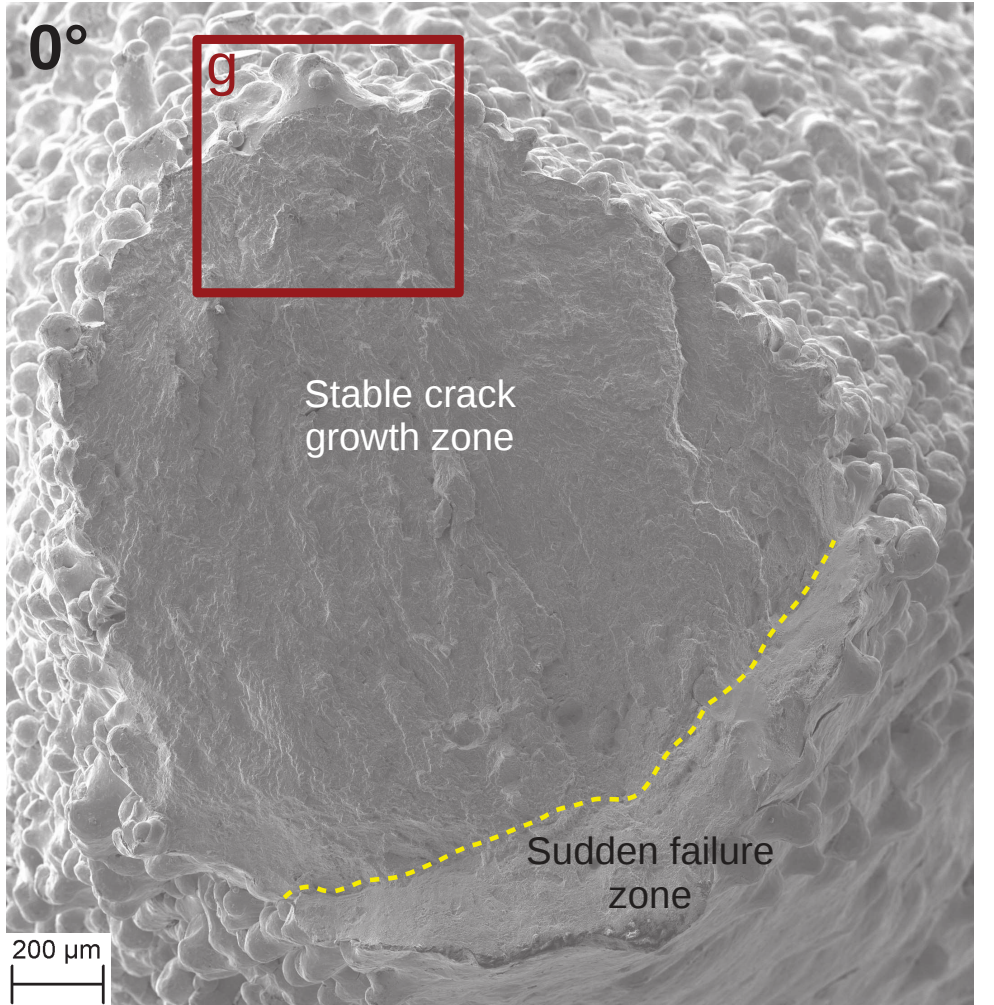

b)

c)

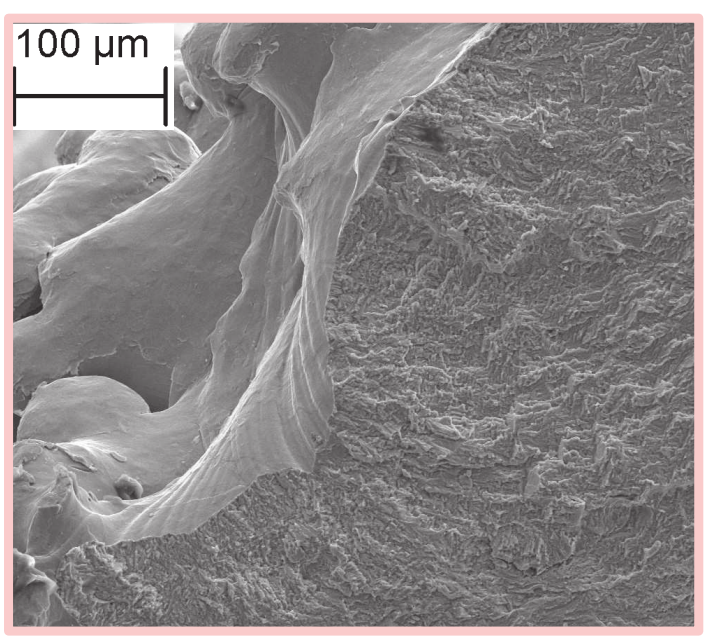

)

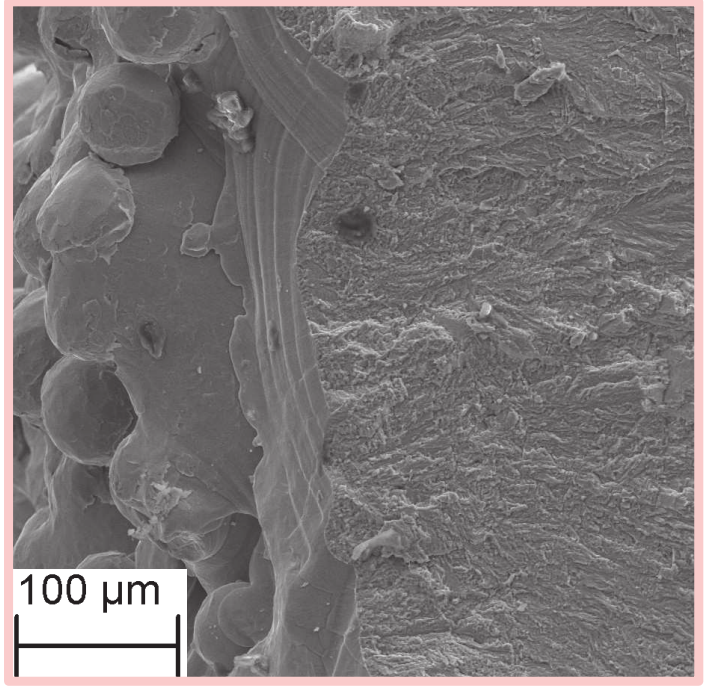

e)

g)
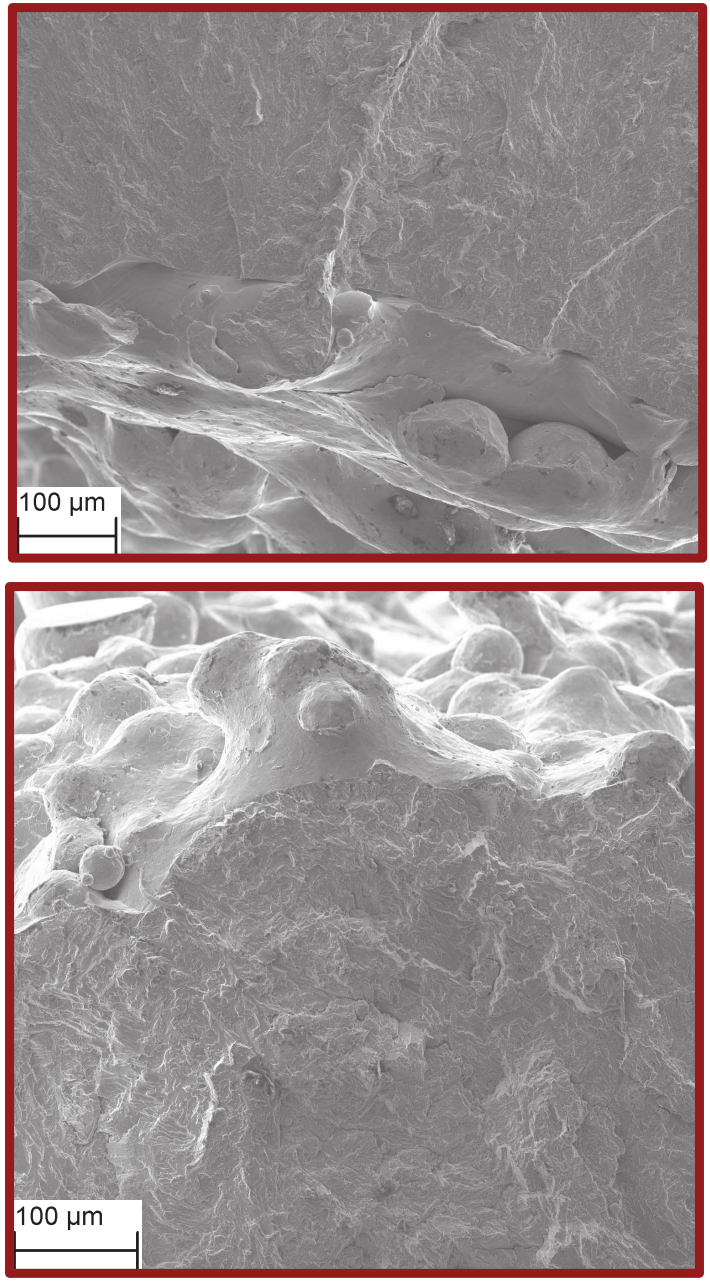
fig_geom-sampletentv3.pdf

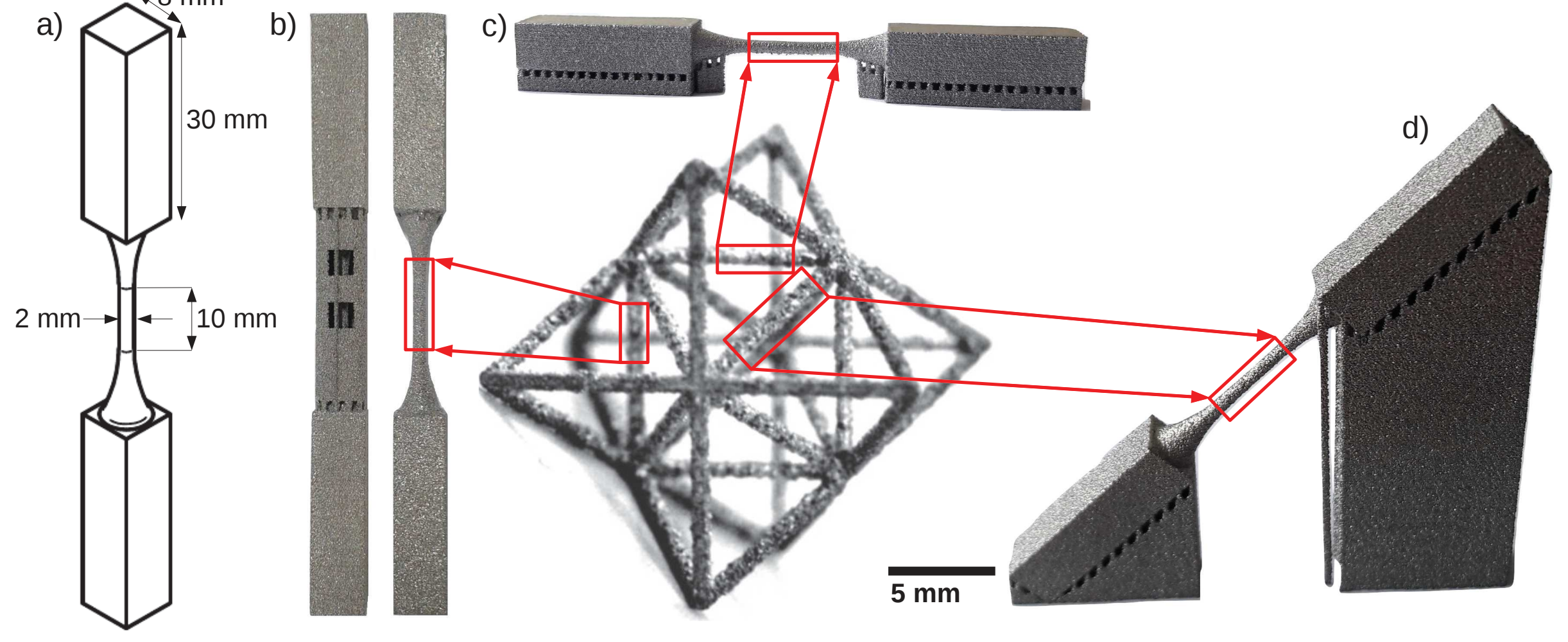


fig_pores-distrib.pdf $0^{\circ}$

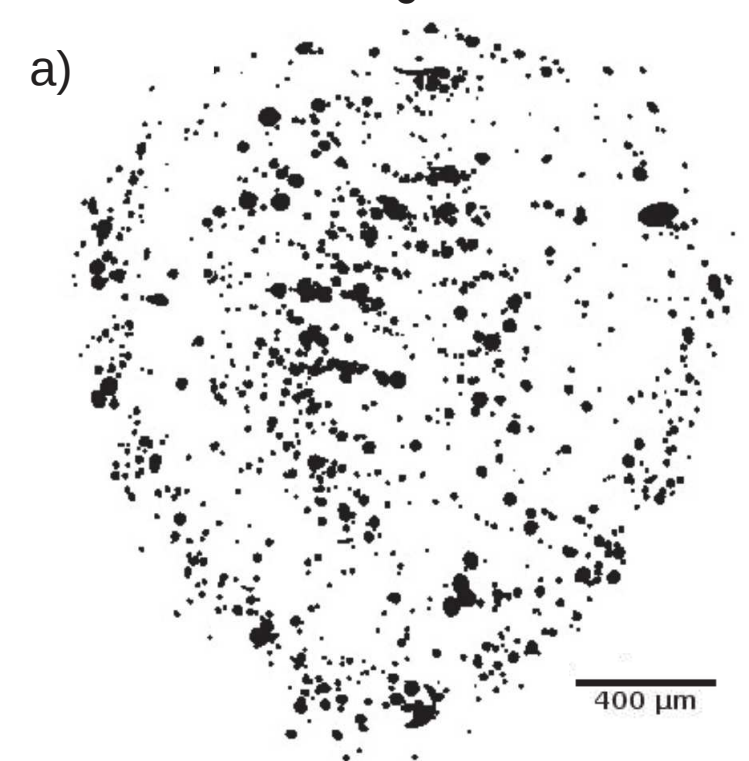

$45^{\circ}$

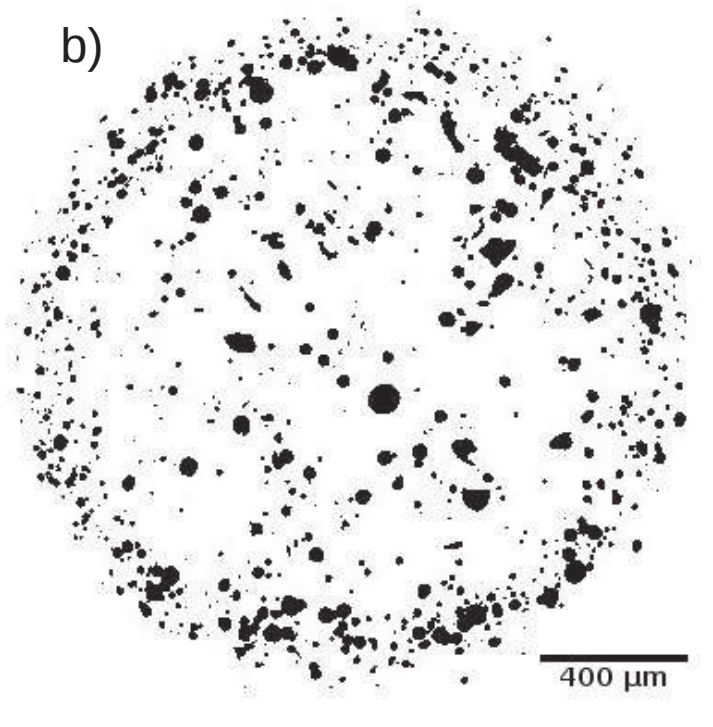

$90^{\circ}$

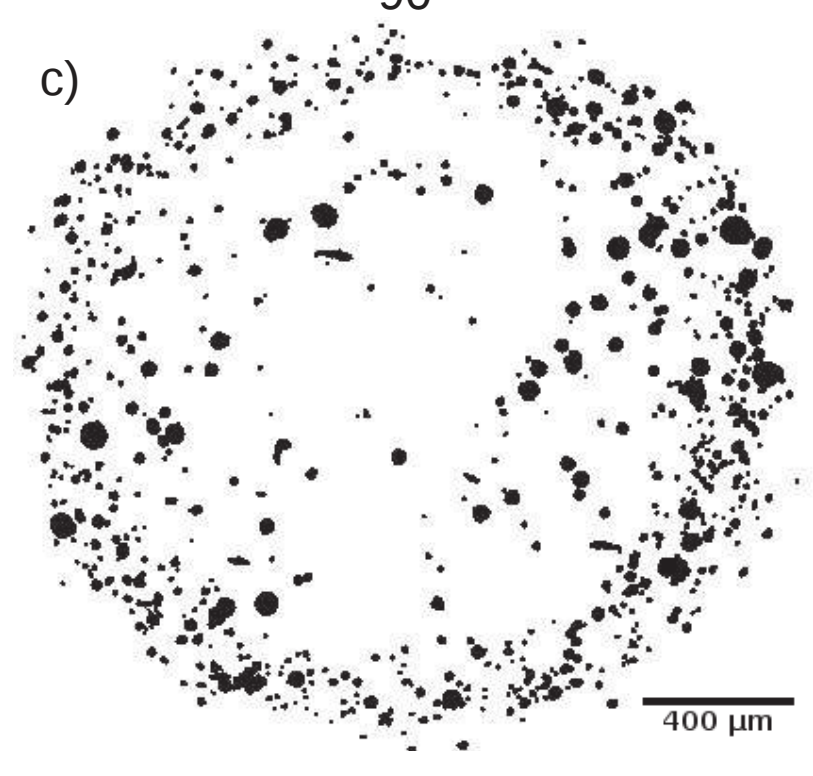




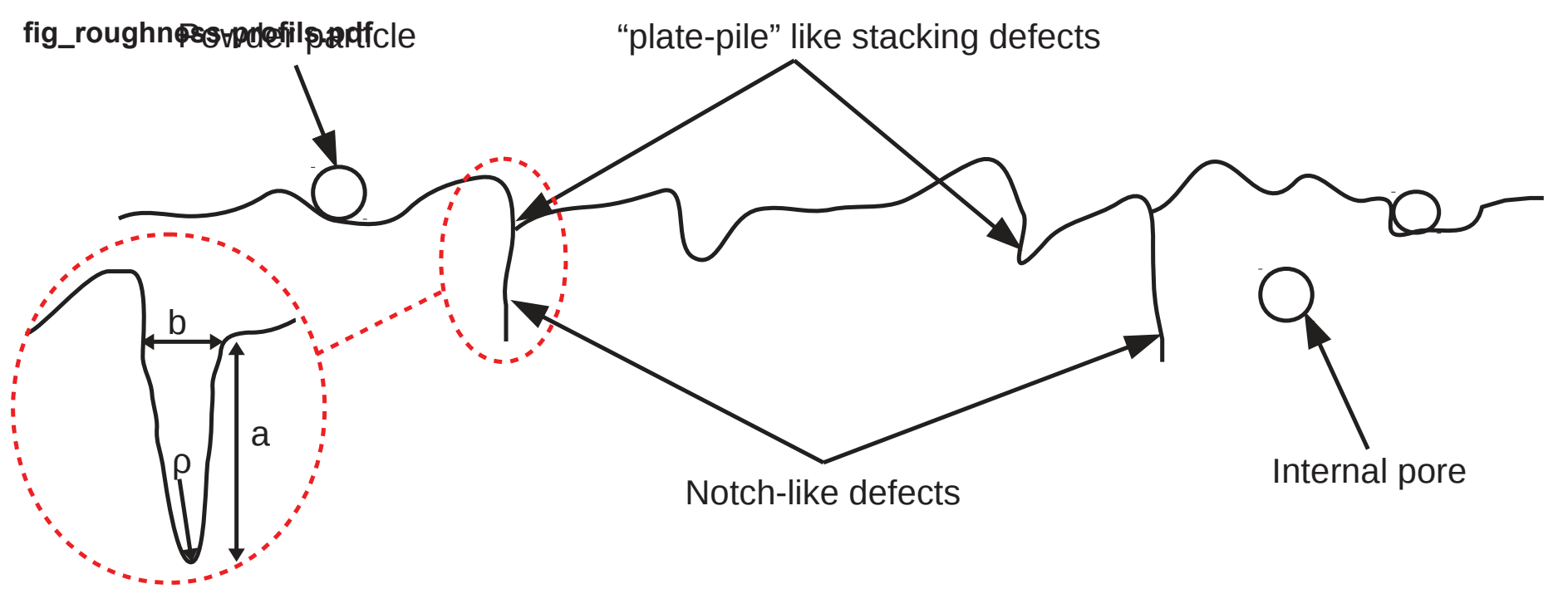




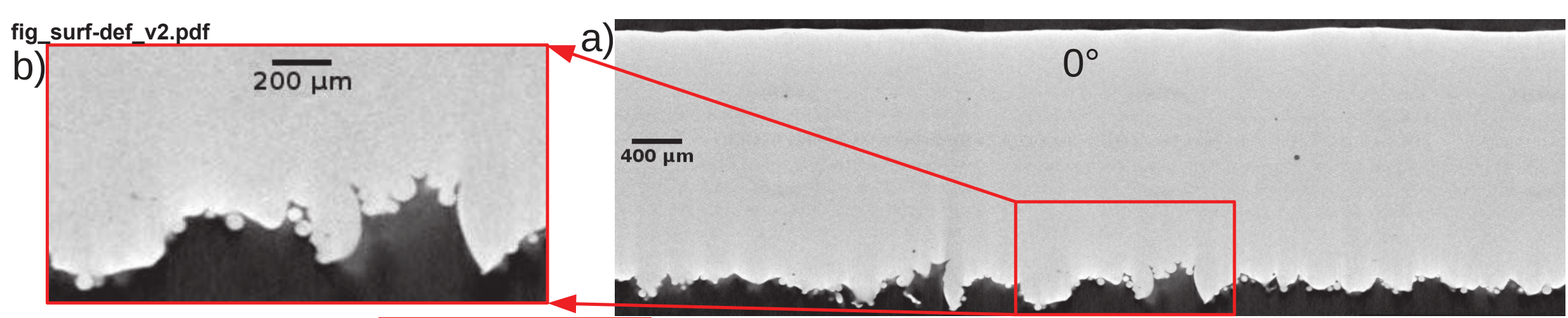

c)

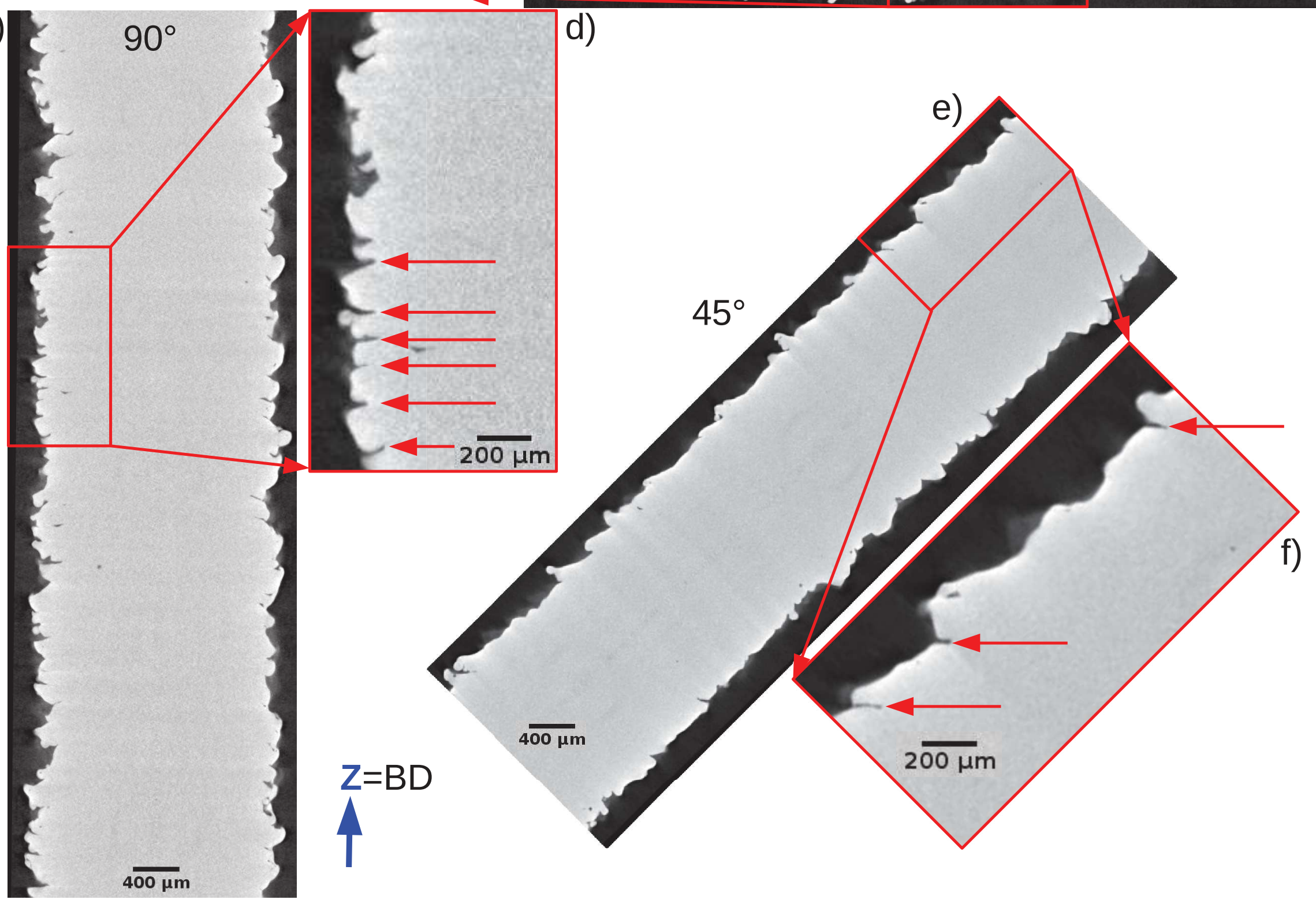

